Document downloaded from:

http://hdl.handle.net/10251/62440

This paper must be cited as:

Miranda Alonso, MÁ.; Cuquerella Alabort, MC.; Lhiaubet ., VL.; Bosca Mayans, F. (2011). Photosensitised pyrimidine dimerisation in DNA. Chemical Science. 2:1219-1232. doi:10.1039/c1sc00088h.

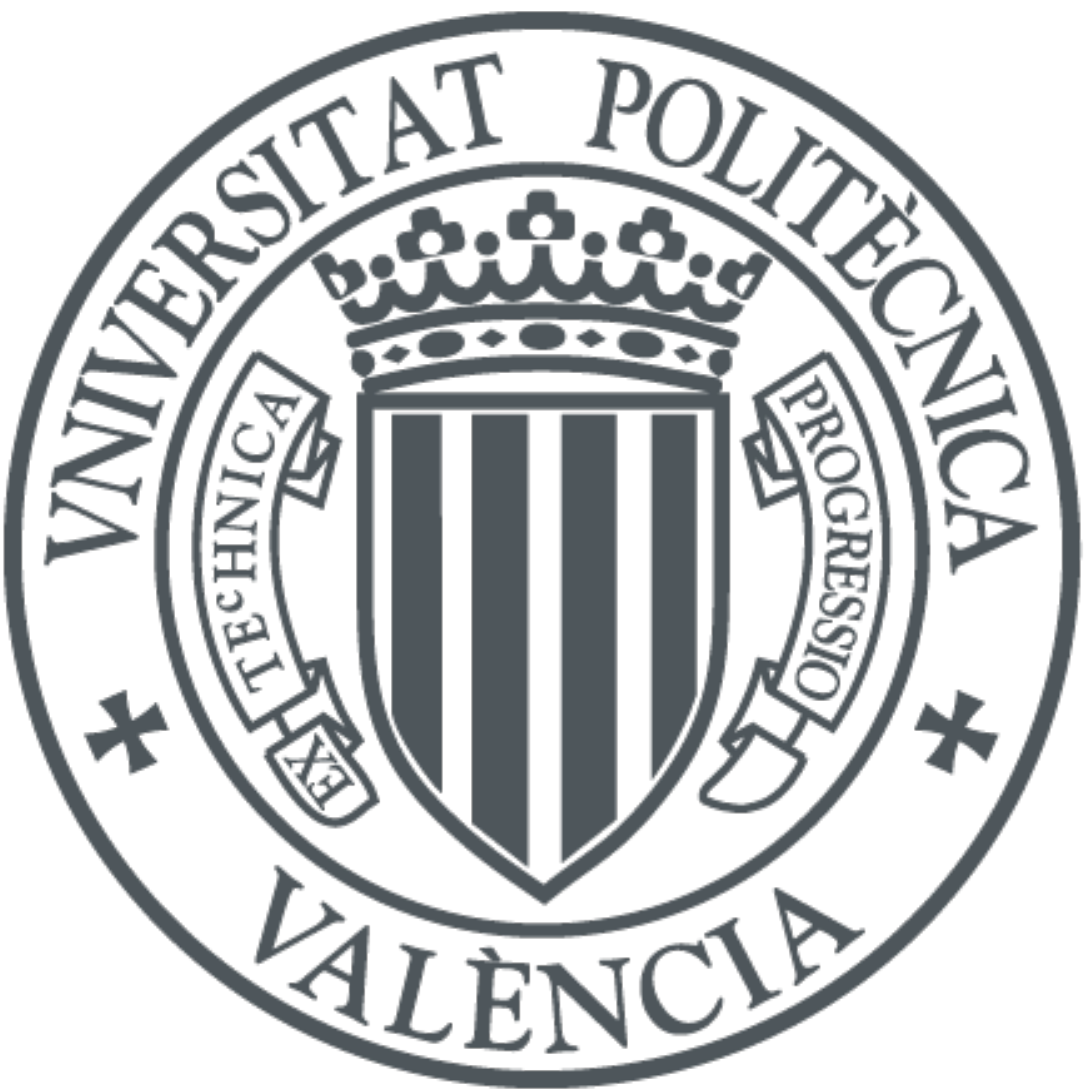

The final publication is available at

http://dx.doi.org/10.1039/c1sc00088h

Copyright Royal Society of Chemistry

Additional Information 


\title{
Photosensitised pyrimidine dimerisation in DNA
}

\author{
M. Consuelo Cuquerella, ${ }^{a}$ Virginie Lhiaubet-Vallet, ${ }^{a}$ Francisco Bosca ${ }^{a}$ and Miguel A. Miranda ${ }^{* a}$
}

\begin{abstract}
5 Triplet-mediated pyrimidine (Pyr) dimerisation is a key process in photochemical damage to DNA. It may occur in the presence of a photosensitiser, provided that a number of requirements are fulfilled, such as favourable intersystem crossing quantum yield and high triplet energy. The attention has been mainly focused on cyclobutane pyrimidine dimers, as they are by far the most relevant Pyr photoproducts obtained by sensitisation. The present perspective deals with the 10 involved chemistry, not only in DNA but also in its simple building blocks. It also includes the photophysical characterisation of the Pyr triplet excited states, as well as a brief discussion of the theoretical aspects.
\end{abstract}

\section{Introduction}

15 Ultraviolet solar radiation reaching the Earth's surface comprises wavelengths ranging from 290 to $320 \mathrm{~nm}$ (UVB) and 320 to $400 \mathrm{~nm}$ (UVA). Both UVB and UVA radiations have been demonstrated to induce mutations in DNA that are in the origin of skin cancer. This is a public health problem, 20 aggravated by the increasing use of tanning sunbeds by the general public. Tanning lamps are intended to produce UVA, but they also emit marginally in the UVB. Recently (July 2009) the International Agency for Research of Cancer (IARC) has declared these devices as "carcinogenic to 25 humans", since they have been proven to increase the risk of skin cancer by $75 \%$ when used by people under 30 years old. 2

Although, in principle, longer-wavelength light is less dangerous, it has to be taken into account that defense 30 mechanisms of the human skin towards their deleterious effects are less effective against UVA induced damage. ${ }^{3}$ Actually, a number of reports have appeared on the promutagenic character of UVA radiation. Thus, studies performed on animals (opossum, ${ }^{4}$ fish, ${ }^{5}$ mice $^{6}$ ) suggest that it 35 provokes the formation of papillomas, squamous cell carcinomas (SCC) and melanomas; however, the role played by UVA-mediated oxidative damage to DNA in melanoma induction, using xiphophorus fishes as model, has been recently questioned. ${ }^{5,7}$

40 While UVB is efficiently absorbed by the nucleobases, causing direct photoreactions of DNA, UVA-induced damage is commonly the result of photosensitisation. Thus, modifications in DNA may occur after light absorption by endogenous or exogenous chromophores present in drugs, 45 cosmetic agents, metabolites, etc.

In this context, UVA-photocarcinogenesis has been mostly related to oxidative stress in early studies. Singlet oxygen production and to a lesser extent hydroxyl radical may be involved in the oxidation of guanine (the nucleobase with the 50 lowest redox

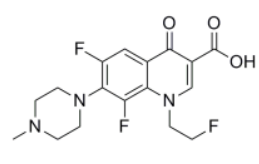

Fleroxacin (FLX)

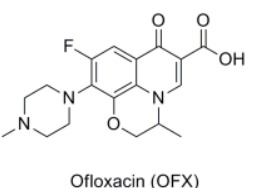

Fig.1 Exogen
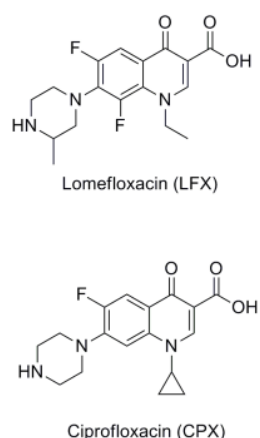

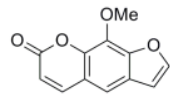

8-Methoxypsoralen (8-MOP)

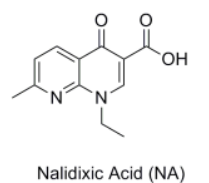

potential), giving rise to 8-oxo-7,8-dihydro-2'deoxyguanosine (8-oxo-dGuo). However, cyclobutane 55 pyrimidine dimers (CPDs) may also arise from UVA irradiation, and their formation yield is even larger than that of 8-oxo-dGuo in human skin. ${ }^{3,8}$ This has been assessed by exposure of healthy human volunteers to UVA light and subsequent analysis of CPDs in their urine or skin. ${ }^{9,} 10$

${ }_{60}$ While the promutagenic character of UVA light is established, the mechanism responsible for UVA photoinduced CPDs formation is a matter of discussion. In particular the possibility of direct UVA-photoinduced damage to DNA, in addition to photosensitisation by endogenous or ${ }_{65}$ exogenous agents, is still controversial. ${ }^{3,8,11-17}$ It has been claimed that CPDs may be formed after UVA irradiation of isolated or cellular DNA in the absence of a photosensitiser. However DNA hardly absorbs UVA, as required for a molecule to react (first law of photochemistry, Grotthus70 Draper law). As an alternative to direct DNA excitation, the presence of unknown chromophores or the insufficient purity of the UVA sources used in the experiments has been considered. Moreover, cellular DNA irradiations produce less CPDs in comparison with isolated DNA. As it is difficult to 75 estimate the amount of light absorbed by DNA under these conditions, a contribution by endogenous photosensitisers $(i$. $e$. porphyrins, flavins, steroids, quinones) cannot be safely ruled out. 
The aim of the present perspective article is to present the case of UVA-photosensitised damage to DNA, with special emphasis on the molecular mechanisms involved in the formation of CPD lesions. A better understanding of these 5 processes should contribute to minimise the photobiological risk.

Among the exogenous agents reported to be photogenotoxic, phototumorigenic and photocarcinogenic in vivo, psoralens (used in the PUVA treatment of psoriasis) ${ }^{18-21}$ 10 and more recently fluoroquinolones (FQs), have received special attention (Fig. 1). The latter are widely used, broad spectrum antibacterial drugs. They are known to induce UVAmediated oxidatively damaged $\mathrm{DNA}^{22-25}$ and their phototumorigenic potential has been proven in mice. ${ }^{26-29}$ 15 Irradiation of albino Swiss and skh-1 hairless mice with UVA light, varying the time of exposure and the drug doses, has established that fleroxacin (FLX) and lomefloxacin (LFX) are more potent phototumorigenic agents than 8-methoxypsoralen (8-MOP). Development of SCCs after the intake of FLX or 20 LFX, together with other lesions such as benign papillomas, solar keratoses or kerato-acanthomas has also been observed in the rodents. Likewise, ofloxacin (OFX), ciprofloxacin (CPX) and the related compound nalidixic acid (NA) have also been found to enhance the development of skin tumours.

25 In vivo studies on xeroderma pigmentosum mice have also revealed LFX as a photocarcinogenic agent. These mice present an inefficient nucleoside excision repair activity for the enzymatic removal of $\mathrm{CPDs}^{29}$ while conserving the capability to repair oxidatively damaged DNA. Exposure of 30 mice to low UVA doses insufficient to provoke severe phototoxic reactions, leads to a large number of SCCs after only 5 weeks; by contrast, control animals require 23 weeks to show similar effects.

\section{Photosensitised formation of cyclobutane pyrimidine dimers}

Photosensitised CPDs formation takes place through a formal [2+2] cycloaddition between the C5-C6 double bonds of two pyrimidines (Pyr). Thus, a photosensitiser (Phs) is excited upon light absorption and then transfers its energy to a 40 pyrimidine base, giving rise to thymine or cytosine excited states $\left(\mathrm{Thy}^{*}\right.$ or $\mathrm{Cyt}^{*}$ ). These states are able to react with ground state Thy or Cyt leading to the final products (Schemes 1 and 2).

$$
\begin{aligned}
& \text { 1) } \mathrm{Phs}^{*}+\mathrm{Pyr} \longrightarrow \mathrm{Phs}+\mathrm{Pyr}^{*} \\
& \text { 2) } \mathrm{Pyr}+\mathrm{Pyr}^{*} \longrightarrow \mathrm{Pyr} \diamond \mathrm{Pyr}
\end{aligned}
$$

Scheme 1 Key processes involved in photosensitised Pyr dimerisation

In general, sensitised photocycloadditions are known to proceed through a triplet-triplet energy transfer (TTET) process. As a consequence, a number of requirements should be fulfilled by the Phs of choice: i) to absorb light at longer 50 wavelengths than Pyr, thus allowing for selective excitation, ii) to have a triplet energy above that of Pyr, as requested for thermodynamically favoured process (Scheme 2), iii) to be

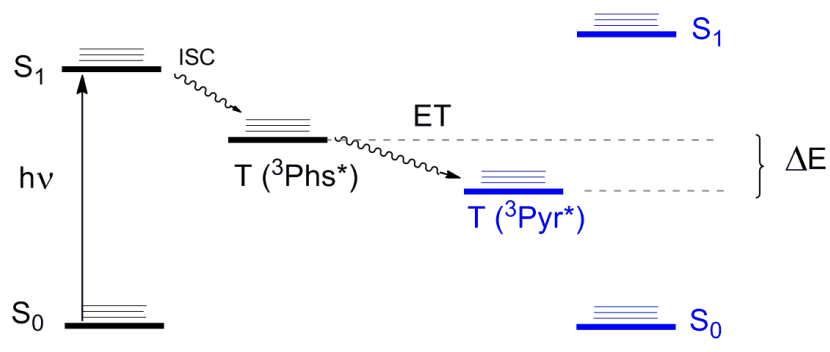

Photosensitiser Pyrimidine

Scheme $\mathbf{2}$ Interconversion between the excited states involved in photosensitised Pyr dimerisation

chemically inert under the reaction conditions, avoiding formation of byproducts and consumption of the Phs, iv) to have a good intersystem crossing quantum yield $\left(\phi_{\text {ISC }}\right)$ and a long triplet lifetime $\left(\tau_{\mathrm{T}}\right)$, in order to increase the probability of 60 energy transfer to an acceptor, and v) to be close enough to the Pyr unit, thereby facilitating collision.

\subsection{Efficiency of photosensitised pyrimidine dimerisation}

In a TTET process, the energy transfer rate constant $\left(\mathrm{k}_{\mathrm{ET}}\right)$ between the Phs (donor) and the Pyr (acceptor) depends on the 65 energy gap $(\Delta \mathrm{E})$, as shown by Sandros' equation:

$$
k_{E T}=k_{D} \frac{1}{\left(e^{-\Delta E / R T}+1\right)}
$$

where $\mathrm{k}_{\mathrm{D}}$ is the diffusion rate constant in liquid solutions. ${ }^{30}$

In this context, a favourable value of $\Delta \mathrm{E}$ is directly related to CPDs formation and therefore to the phototumorigenic 70 capability of endo- or exogenous agents acting as Phs. Thus, it is of paramount importance to establish Pyr triplet excited state energies $\left({ }^{3} \mathrm{Thy}^{*},{ }^{3} \mathrm{Cyt}^{*}\right)$ to anticipate the potential of a compound to act as Phs. Consequently, an effort has been made in this sense, with special attention to ${ }^{3}$ Thy in DNA, 75 where $\pi$-stacking and base pairing can have a marked influence on the triplet excited state properties.

In addition to $\Delta \mathrm{E}$ and temperature ${ }^{18}$ (as inferred from eq. 1), photoproducts formation and distribution are influenced by parameters such as the nature of the lowest lying triplet state 80 of the Phs, ${ }^{31}$ the solvent, ${ }^{32}$ the concentration of Pyr used, etc.

The importance of Pyr concentration deserves a special comment. According to Scheme 1, ground state Pyr quenches both ${ }^{3} \mathrm{Phs}^{*}$ and ${ }^{3} \mathrm{Pyr}^{*}$, so the reaction rates should increase with increasing $\mathrm{Pyr}$ concentration. In practical terms, 85 photodimerisation quantum yields $\left(\phi_{\mathrm{D}}\right)$ are reproducible only upon complete quenching of the involved triplet excited states. Accordingly, only a limited number of $\phi_{D}$ values are available (Table 1), due to the experimental difficulties to cover all the above requirements; they range between $10^{-2}$ and $9010^{-5}$. The values are consistent with the upper limit established by measurements performed using acetonitrile (0.02), where formation of cyclobutane thymine dimers (Thy<>Thy) is assumed to occur almost exclusively through the triplet excited state. ${ }^{33}$ 
<smiles>[R]C1C2NC(=O)NC(=O)C2(C)C2(C)C(=O)NC(=O)NC12</smiles>

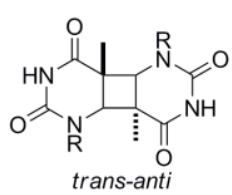<smiles></smiles><smiles></smiles>
cis-anti

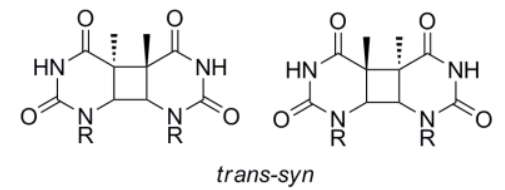

$\mathrm{R}=\mathrm{H}$; Thymine

$\mathrm{R}=$ 2-deoxy-D-ribose; Thymidine
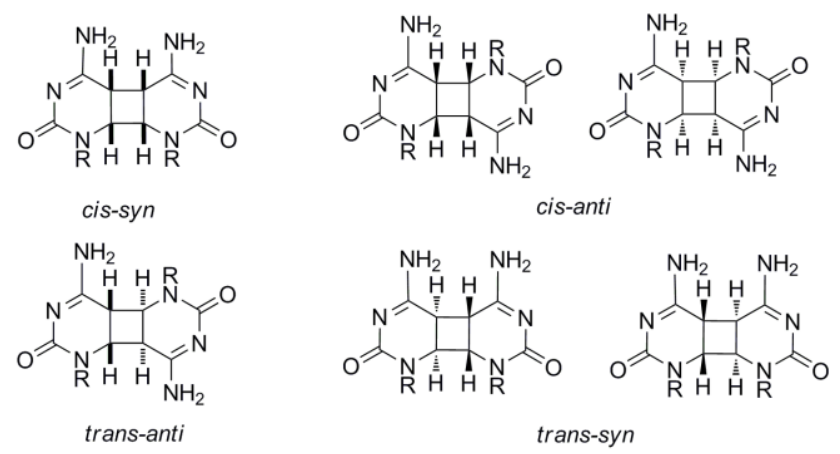

$\mathrm{R}=\mathrm{H} ;$ Cytosine

$\mathrm{R}=$ 2-deoxy-D-ribose; Deoxycytidine

Fig. 2 Structures of all possible homodimers formed after UVA-photosensitised irradiation of Pyr

\subsection{Pyrimidine photoproducts in DNA building blocks}

5 In principle, Thy $<>$ Thy, Cyt $<>$ Thy, and Cyt $<>$ Cyt dimers can be formed by photosensitisation of solutions containing the appropriate monomers. Different regio-and diastereoisomers may be obtained in solution (see Fig. 2). ${ }^{34}$ It is worth noting that the cis-anti and trans-syn isomers exist as enantiomeric 10 pairs in Thy and Cyt and as diastereomeric pairs in thymidine (Thd) and 2-deoxycytidine (dCyd). Thus a total of 6 isolable diastereomeric homodimers can be obtained from the nucleosides, as compared with 4 in the case of the free bases. $^{34,35}$

15 Although crossed cycloadditions are, in principle, possible to form Thy $<>$ Cyt heterodimers, photosensitised formation of these CPDs has not been described. In this context, Thy dimers have received special attention, since they are the most abundant dimers formed in DNA. $6,8,15,36$

${ }_{20}$ Table 1 Quantum yields of photosensitised pyrimidine dimerisation.

\begin{tabular}{|c|c|c|c|}
\hline Substrate & Concentration & Photosensitiser & $\phi_{\mathrm{D}}$ \\
\hline \multirow{4}{*}{ Thy } & \multirow{4}{*}{$1 \times 10^{-2} \mathrm{M}^{\mathrm{a}}$} & Acetone $^{37}$ & 0.0042 \\
\hline & & Acetophenone ${ }^{37}$ & 0.0016 \\
\hline & & $\mathrm{BP}^{37}$ & 0.011 \\
\hline & & $\mathrm{PABA}^{38}$ & 0.0007 \\
\hline \multirow{4}{*}{ DMT $^{\mathrm{c}}$} & $0.1 \mathrm{M}^{\mathrm{b}}$ & $\mathrm{BP}^{39}$ & 0.023 \\
\hline & $0.05 \mathrm{M}^{\mathrm{b}}$ & & 0.017 \\
\hline & $0.1 \mathrm{M}^{\mathrm{b}}$ & Acetophenone ${ }^{39}$ & 0.061 \\
\hline & $0.2 \mathrm{M}^{\mathrm{b}}$ & & 0.031 \\
\hline \multirow{3}{*}{$\begin{array}{c}\text { Supercoiled } \\
\text { DNA }\end{array}$} & \multirow{3}{*}{$\begin{array}{l}18.85 \mu \mathrm{M} \text { in base } \\
\text { pairs }\end{array}$} & Tiaprofenic acid & 0.00001 \\
\hline & & Ketoprofen ${ }^{40}$ & 0.0002 \\
\hline & & Acetophenone ${ }^{40}$ & 0.006 \\
\hline Phage T4 & - & $\begin{array}{c}\text { Cationic } \\
\text { acetophenone }\end{array}$ & 0.03 \\
\hline \multicolumn{4}{|c|}{ 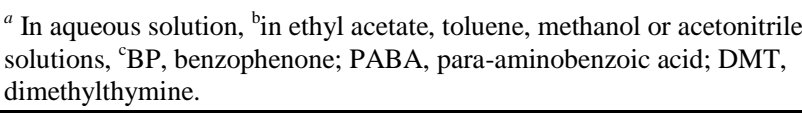 } \\
\hline
\end{tabular}

\section{2.2.1 Thymine and thymidine photosensitisation}

There are a limited number of compounds, including nonsteroidal anti-inflammatory drugs (NSAIDS), cosmetic agents like para-aminobenzoic acid (PABA), ketones or pyridopsoralens (PyPs), able to photoinduce CPDs formation 30 in free nucleobases or nucleosides; among them PyPs and ketones are very illustrative examples (Fig. 3).

When pyridopsoralens with different triplet energies $\left(\mathrm{E}_{\mathrm{T}}\right)$, namely, pyrido[3,4-c]psoralen (H-PyPs, $\mathrm{E}_{\mathrm{T}}=290.4 \mathrm{~kJ} / \mathrm{mol}$ ), 7-methylpyrido[3,4-c]psoralen (MePyPs, $\mathrm{E}_{\mathrm{T}}=288.5 \mathrm{~kJ} / \mathrm{mol}$ ) 35 and 7-methylpyrido[4,3-c]psoralen (2N-MePyPs, $\mathrm{E}_{\mathrm{T}}=281.7$ $\mathrm{kJ} / \mathrm{mol}$ ) are irradiated in thin films in the presence of Thy, Thy <> Thy dimers are obtained with the cis-syn isomer as the most abundant one. ${ }^{18}$ Products yields correlate with the PyPs triplet energies, as expected from Sandros' equation. ${ }_{40}$ Furthermore, parallel irradiations with the related compounds 5-methoxypsoralen (5-MOP, $\mathrm{E}_{\mathrm{T}}=268.2 \mathrm{~kJ} / \mathrm{mol}$ ) and 8 -MOP $\left(\mathrm{E}_{\mathrm{T}}=260.5 \mathrm{~kJ} / \mathrm{mol}\right)$ show very little if any photosensitised dimer formation.

A clear example of the temperature effect is provided by an ${ }_{45}$ experiment performed with H-PyPs. Photoinduced Thy $<>$ Thy formation at $77 \mathrm{~K}$ is two orders of magnitude less efficient than at $300 \mathrm{~K}$. Photosensitisers with $\mathrm{E}_{\mathrm{T}}$ lower than that of ${ }^{3} \mathrm{Pyr}^{*} 18,42,43$ can still work upon thermal population of the ${ }^{3} \mathrm{Phs}{ }^{*}$ upper vibrational states. Even if formed in low yields, 50 the resulting CPDs would be of biological significance. ${ }^{18,31}$

In this context, distribution of the photodimers mixture can be influenced by the polarity of the solvent. Thus, benzophenone (BP) photosensitisation of 1,3-dimethylthymine (DMT) leads to the cis-syn isomer as major photoproduct in 55 polar solvents $\left(\sim 72 \%, \mathrm{CH}_{3} \mathrm{CN}\right.$ and $\left.\mathrm{CH}_{3} \mathrm{OH}\right)$ while in nonpolar solvents the cis-anti one predominates $(\sim 50 \%$, benzene). ${ }^{32,39}$

Ketones have often been used to photosensitise CPDs formation taking advantage of their high $\phi_{\text {ISC }}$ (nearly 1). ${ }^{32,37}$, ${ }_{60}{ }^{44-49}$ Irradiation of aqueous solutions of Thy (or Thd) in the presence of acetone, propiophenone, acetophenone or benzophenone gives rise to a mixture of isomers (Fig. 2), with certain prevalence of the trans-anti diastereomers. ${ }^{44,46-48}$ 
<smiles>[R]Nn1cc(C)c(=O)[nH]c1=O</smiles><smiles>[R]n1cc(C)c(=O)[nH]c1=O</smiles><smiles>[Y][Y](=O)(=O)O</smiles><smiles>[R]N1C(=O)NC(=O)C(C)(O)C1O</smiles>

Scheme 3 Mechanistic pathways involved in the photosensitised oxidation of thymidine by benzophenone

Interestingly, ketones can also mediate oxidation of $\mathrm{Pyr}$ 5 bases given their ability to participate in hydrogen abstraction or electron transfer processes ${ }^{50}$ (Scheme 3). Nonetheless, in the case of dinucleotides such as $\mathrm{TpT}^{48}$ energy transfer prevails (ca. $94 \%$ ) over BP-photosensitised oxidation.

\section{2.2.2 Cytosine and 2-deoxycytidine photosensitisation}

Although early attempts to photosensitise Cyt $<>$ Cyt formation with $\mathrm{BP}$, acetone or acetophenone were unsuccessful, ${ }^{37}$ later work has reported on three dimers of Cyt/dCyd in aqueous acetone (trans-anti, cis-syn and cis-anti, Fig. 2) ${ }^{35}$ This type of 15 photoproducts have not attracted special attention, since their photosensitised formation in DNA occurs with comparatively low yields (see below); however Cyt containing CPDs are biologically relevant due to their high mutagenic potential. Besides, Cyt dimers deaminate easily when formed, giving 20 rise to complex mixtures of dimers with random combination of Cyt and uracil (Ura) units. Interestingly, nucleoside deamination has been found to be six times faster than that of the nucleotide.

\section{${ }_{25}$ 2.2.3 Byproducts of the photoreaction of triplet sensitisers with pyrimidines}

As stated above, a Phs must be chemically inert. Otherwise, secondary reactions can occur giving rise to misleading results, such as formation of byproducts and overestimation of 30 the photoreaction quantum yields. This is the case of PyPs and ketones (Fig. 4).

For example, PyPs possess a double bond in their furan moiety prone to react through a $[2+2]$ crossphotocycloaddition with the C5-C6 double bond of Pyr. 35 Actually, when CPDs formation is photosensitised by PyPs, this type of photoaddition is indeed observed. ${ }^{19}$ Likewise in the acetone photosensitised reaction of Thd an acetonyl derivative has been isolated as a side product. $^{34}$

Furthermore, carbonyl compounds may in principle react 40 with alkenes to form oxetane derivatives through a [2+2] photocycloaddition (Paterno-Büchi reaction). This process is favoured when i) the triplet energy of the alkene is comparable to (or higher than) that of the carbonyl compound and ii) the lowest lying carbonyl triplet state is of $n \pi^{*}$ nature. ${ }_{45}$ As a consequence, ketones with relatively low triplet energy may lead to oxetane derivatives of Pyr, in addition to CPDs. ${ }^{51-}$ 53 This is the case of $\mathrm{BP}::^{31,44}$ its triplet excited state, which presents a $n \pi^{*}$ configuration, has an $E_{T}$ level below that of acetone or acetophenone. As a matter of fact, a Paterno-Büchi 50 reaction giving rise to oxetanes is favoured versus TTET (Scheme 4). Only when Thd is present at high concentrations CPDs are obtained. ${ }^{31,} 50$ Similar observations have been reported for NSAIDs containing the BP chromophore, such as ketoprofen (KP) and its derivatives. ${ }^{51,52,54,55}$ Similarly, a 55 photocycloaddition product identified as an oxetane has been described after irradiation of cytosine in acetone-aqueous $(1: 1)$ solutions. $^{53}$

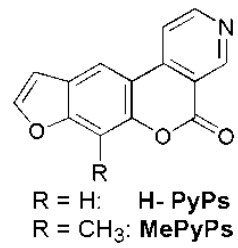<smiles>Cc1c2occc2cc2c1oc(=O)c1ccncc12</smiles>

2N-MePyPs<smiles>[R2]c1c2ccoc2c([R2])c2oc(=O)ccc12</smiles>

$\mathrm{R}_{1}=\mathrm{H}_{1} \mathrm{R}_{2}=\mathrm{OCH}_{3}: \mathbf{5}-\mathrm{MOP}$

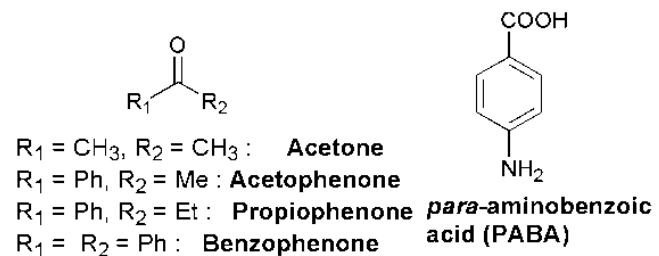

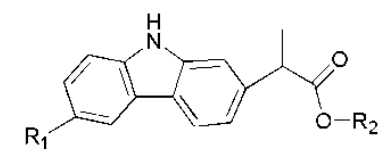

$\mathrm{R}_{1}=\mathrm{Cl}, \mathrm{R}_{2}=\mathrm{H}$; Carprofen (CP) $\mathrm{R}_{1}=\mathrm{H}_{1} \mathrm{R}_{2}=\mathrm{H}_{i}$ CP photoproduct (PP) $\mathrm{R}_{1}=\mathrm{R}_{2}=\mathrm{CH}_{3}$, PP Ester (PPE)<smiles>[R]c1ccc(C(=O)c2ccc([R3])c([R2])c2)cc1</smiles>

$\mathrm{R}_{1}=\mathrm{H}, \mathrm{R}_{2}=\mathrm{CHCH}_{3} \mathrm{COOH}, \mathrm{R}_{3}=\mathrm{H} ;$ Ketoprofen (KP)

$\mathrm{R}_{1}=\mathrm{Cl}, \mathrm{R}_{2}=\mathrm{H} ; \mathrm{R}_{3}=\mathrm{OC}\left(\mathrm{CH}_{3}\right)_{2} \mathrm{COOH} ;$ Fenofibric acid (FA)

$\mathrm{R}_{1}=\mathrm{Cl}, \mathrm{R}_{2}=\mathrm{H} ; \mathrm{R}_{3}=\mathrm{OC}\left(\mathrm{CH}_{3}\right)_{2} \mathrm{COOCH}\left(\mathrm{CH}_{3}\right)_{2}$; Fenofibrate (FB)<smiles>COc1cc(O)c(C(=O)c2cc(S(=O)(=O)O[Na])c(OC)cc2O)cc1S(=O)(=O)[O-]</smiles>

Disodium 2,2'-dihydroxy-4,4'-

dimethoxybenzophenonesulphonic acid (benzophenone-9)

Fig. 3 Photosensitisers for Pyr dimerisation 


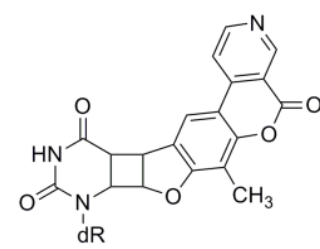

MePyPs-Thd photoadduct

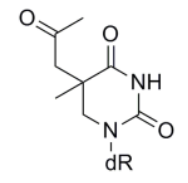

5-acetonyl-5,6-dihydrothymidine

Fig. 4 Structures of byproducts obtained upon photosensitisation of Thd with PyPs (left) or acetone (right).
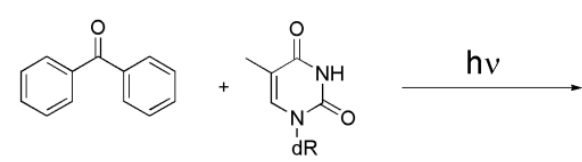

Thymidine (Thd)

Scheme 4 Paterno-Büchi photoreaction between BP and Thd.

\subsection{Oligonucleotides photosensitisation}

Photosensitised CPDs formation has been observed in oligonucleotides and single stranded DNA (ss-DNA). Here, Pyr dimerisation occurs through adjacent Pyr on the same 10 strand, inducing a distortion in the structure. Among the possible cyclobutane dimers, 5'-Thy $<>$ Thy-3', 5'-Cyt $<>$ Thy3' and 5'-Thy $<>$ Cyt-3' are preferentially promoted. However, ${ }^{\prime}$ '-Cyt $<>C y t-3$ ' may be obtained in lower yields. ${ }^{6}$ Since Cyt is the DNA base with the highest triplet energy, a reduced 15 number of photosensitisers can be involved in a thermodynamically favourable TTET. Furthermore, if a fraction of Cyt reaches the triplet excited state, efficient deactivation by energy transfer to the other bases should be expected. $^{36}$

20 In addition, Thy $<>$ Thy predominate over Thy $<>$ Cyt dimers in oligonucleotides and DNA. ${ }^{56}$ For instance, acetophenonemediated photodimerisation of thymidylyl-(3'-5')-thymidine (TpT, Scheme 5) occurs five to six times faster than that of thymidylyl-(3'-5')-deoxycytidine (TpdC). ${ }^{57}$ The energy gap

25 values in terms of Sandros' equation (eq. 1), together with the relative reactivity of ${ }^{3}$ Thy towards Cyt or Thy, would explain the different photodimerisation rates.

Orientation restrictions imposed by the sugarphosphodiester backbone prevent formation of the anti forms 30 and favour the cis-syn arrangement; ${ }^{19,} 35,48,55-59$ nonetheless, trans-syn dimers are also observed in ss-DNA or

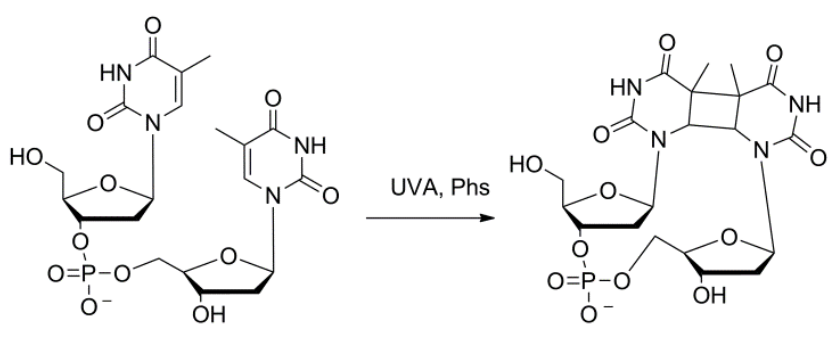

TpT

TpT dimers

Scheme 5 Photosensitised thymidylyl-( $\left.3^{\prime}-5^{\prime}\right)$-thymidine (TpT) dimerisation
35 oligonucleotides owing to their flexible structure. ${ }^{56,60}$ This is the case of $\mathrm{dCpT}, \mathrm{TpdC}$ and $\mathrm{TpT}$, which produce mainly cissyn and trans-syn diastereomers ${ }^{48,61}$ in proportions that may range from $7: 1(\mathrm{TpT})$ to $3: 1(\mathrm{dCpT})$ or $1: 1$ (TpdC). Similar results are obtained when two Thy units are kept in close ${ }_{40}$ proximity through a polymethylene linker. ${ }^{62}$ The largest Thy <> Thy yield is obtained in the case of Thy- $\left(\mathrm{CH}_{2}\right)_{3}$-Thy, likely because the angle between the two Thy approaches that in DNA. Only the intramolecular photodimerisation of some $N$-acetylated dinucleotides gives rise exclusively to the trans${ }_{45}$ syn configuration, presumably due to steric hindrance. ${ }^{63}$

The influence of the Thy-Thy distance has also been evaluated by comparing the reaction rates and Thy $<>$ Thy formation yields of poly( $\mathrm{T})$ and depurinated poly $(\mathrm{dA}-\mathrm{T})$. In both cases, Thy<>Thy dimers are formed, albeit the reaction 50 rate is slowed down in the latter due to the poorer $\pi$-stacking and longer base-to-base distance. Conformation has a pronounced effect on CPDs formation by governing the extent of stacking between the bases. This is further supported by the fact that dimerisation efficiency is reduced after denaturation 55 by addition of a suitable solvent like ethanol. ${ }^{36,64,65}$

The outcome of dimerisation does not only depend on the conformation but also on the nucleobases sequence. ${ }^{66}$ The frequency of CPDs lesions increases when a Pyr is located in the 5' side of two consecutive Thy. ${ }^{56,67-70}$ Studies performed ${ }_{60}$ by means of ${ }^{32} \mathrm{P}$ radiolabelling and subsequent electrophoresis combined with specific DNA repair enzymes, have shown that photosensitised $\mathrm{Pyr}<>\mathrm{Pyr}$ formation in a 25-mer 5'-TGA GCG TTA GTT TAA GTC GGC TATC-3' by ketonic drugs occurs more frequently in TTT fragments.

\section{${ }_{65}$ 2.4 DNA photosensitisation}

While UVA-photosensitisation of DNA gives rise exclusively to CPDs, direct UVB irradiation also produces pyrimidine (64) pyrimidone photoproducts. ${ }^{16}$ This strongly suggests the involvement of two different mechanisms.

70 As in oligonucleotides, DNA photosensitisation produces Thy $<>$ Thy, 5'-Cyt $<>$ Thy-3' and 5'-Thy $<>$ Cyt-3', together with small amounts of $\mathrm{Cyt}<>\mathrm{Cyt}$ in adjacent pyrimidines on the same strand, with an overwhelming predominance of cissyn Thy<>Thy. Analysis of these lesions is often performed 75 by radiolabelling and subsequent electrophoresis. $25,71,72$ Single cell electrophoresis (comet assay) has been successfully used to reveal cellular DNA damage, as fragmented DNA moves faster through the agarose gel, forming a tail. ${ }^{73,74}$ Both methods can be combined with 80 specific repair enzymes to reveal the type of damage produced.

Relative Pyr $<>$ Pyr formation yields are listed in Table 2. For example, irradiation of DNA using BP or acetophenone as Phs does not produce detectable amounts of Cyt $<>C y t$. Only 85 acetone photosensitisation leads to Cyt homodimers, ${ }^{8,} 56,75,76$ presumably due to the higher $\mathrm{E}_{\mathrm{T}}$. In general, 5'-Cyt $<>$ Thy-3' and 5'-Thy<>Cyt-3' photosensitisation is inefficient as compared to Thy $<>$ Thy, although in ct-DNA and coliphage M13 considerable amounts of heterodimers are obtained. For 90 comparison, in direct DNA photolysis the relative formation yields are 1:0.8:0.2 (TT:CT:CC). ${ }^{36}$ 
Table 2 Relative Pyr <>Pyr formation yields after UVA irradiation of different types of DNA in the presence of ketones

\begin{tabular}{|c|c|c|c|c|c|c|c|c|}
\hline & \multirow{2}{*}{$\frac{\mathbf{B P}^{\mathrm{a}}}{\mathbf{a}}$} & \multicolumn{5}{|c|}{ Acetophenone $^{\mathrm{a}, \mathrm{b}, \mathrm{c}, \mathrm{d}, \mathrm{e}}$} & \multicolumn{2}{|c|}{ Acetone $^{\mathrm{e}, \mathrm{f}}$} \\
\hline & & $\mathbf{a}$ & $\mathbf{b}$ & c & d & $\mathbf{e}$ & $\mathbf{e}$ & f \\
\hline Thy<>Thy & 0.2 & 1 & 1 & 1 & 1 & 0.65 & 1 & 1 \\
\hline $\begin{array}{l}\text { Thy<>Cyt } \\
\text { Cyt }<>\text { Thy }\end{array}$ & $\begin{array}{c}0.046 \\
0.05\end{array}$ & $\begin{array}{l}0.24 \\
0.23\end{array}$ & 0.05 & 0.19 & 0.03 & $*$ n.d & 0.12 & $\begin{array}{l}0.20 \\
0.36\end{array}$ \\
\hline Cyt $<>$ Cyt & *n.d. & $*$ n.d. & $*$ n.d. & *n.d. & $<0.003$ & *n.d. & 0.05 & 0.08 \\
\hline
\end{tabular}

${ }^{\mathrm{a}}$ Calf-thymus DNA, ${ }^{8}$ native DNA,${ }^{64 \mathrm{c}}$ denatured DNA,${ }^{64 \mathrm{~d}}$ E. coli DNA, ${ }^{41 \mathrm{e}}$ Phage $\mathrm{T} 7{ }^{77}$ and ${ }^{\mathrm{f}}$ Coliphage M13 mp $2,{ }^{56}{ }^{*}$ n.d. $=$ Not determined. For each experiment, the amount of Thy<>Thy has been set as the unity for comparison.

5 Formation of CPDs in isolated and cellular DNA can be photosensitised not only by ketones, ${ }^{58,76}$ but also by PyPs, ${ }^{19}$, ${ }^{78}$ NSAIDs, ${ }^{40,54,68,79} \mathrm{FQs}^{23,25,29,71-74,80,81}$ amino acids and derivatives $^{59,82}$ or cosmetic agents ${ }^{83,84}$ (Fig. 5). Studies performed on Thy dimerisation by the FQ family have played 10 a key role in determining the triplet energy of Thy in DNA at ca $267 \mathrm{~kJ} / \mathrm{mol}$. Dimers formation is mediated by ENX and NFX, while it is not by the N(4')-acetyl NFX derivative (ANFX) or OFX. ${ }^{23,25,71,72}$ Interestingly, for ENX, LFX and NFX the efficiency of CPDs formation has been found to be 15 different in isolated and cellular DNA.

As in oligonucleotides, Thy $<>$ Thy formation in DNA is sequence-dependent. ${ }^{19}, 56,69,78$ Pyridopsoralens H-PyPs, MePyPs and 2N-MePyPs react specially at TTTTA and TTAAT fragments, provoking $40 \%$ and $55 \%$ of Thy $<>$ Thy 20 photolesions, respectively. Moreover, CPDs formation is not detected in a GC environment or at CC sites.

In addition to neighbouring effects, sequence dependence may be the result of selective formation of Phs-DNA complexes in specific DNA locations. Thus, complexation to 25 DNA can place the $\mathrm{Phs}$ and the Pyr units in close proximity favouring TTET processes. As an example, 4',5'-dihydro-7methylpyrido[3,4-c]psoralen, a modified PyPs, binds to DNA close to $5^{\prime}$-TA-3' sites. $^{78}$ If the binding is disrupted (i.e. by varying the ionic strength), Thy dimers formation is 30 negligible. ${ }^{82}$ An additional example is provided by two cationic derivatives: $\beta$-dimethylaminopropiophenone hydrochloride and $N$-( $m$-acetylbenzyl)- $N$-(2-aminoethyl) ammonium dichloride. The charged $\mathrm{Phs}$ are brought close to DNA by ionic interactions, which is reflected in an increased 35 photosensitisation capability with respect to acetophenone. ${ }^{41}$

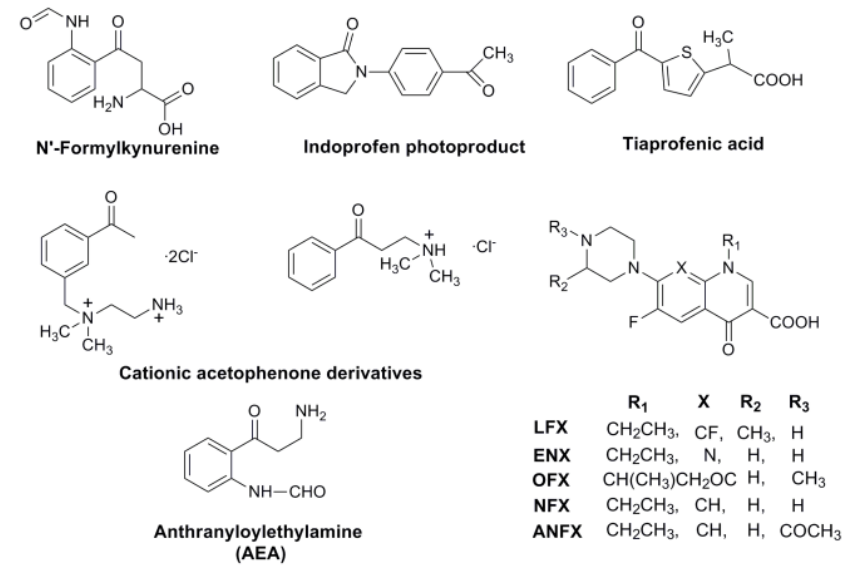

Fig. 5 Photosensitisers for Pyr<>Pyr formation in DNA

\section{Spore photoproducts}

${ }_{40}$ Another interesting dimeric pyrimidine lesion corresponds to the most abundant UV photoproduct in bacterial spores. ${ }^{85,} 86$ Indeed, 5-thyminyl-5,6-dihydrothymine adduct, the so called spore photoproduct (Fig. 6, SP), is formally obtained by linking the allylic carbon to the $\mathrm{C} 5$ position of a neighbouring 45 Thy, with saturation of the C5-C6 double bond. Four isomeric forms of SP may be formed within DNA since a chiral center is generated at C5a carbon. Furthermore, the allylic carbon can be linked to adjacent thymines located
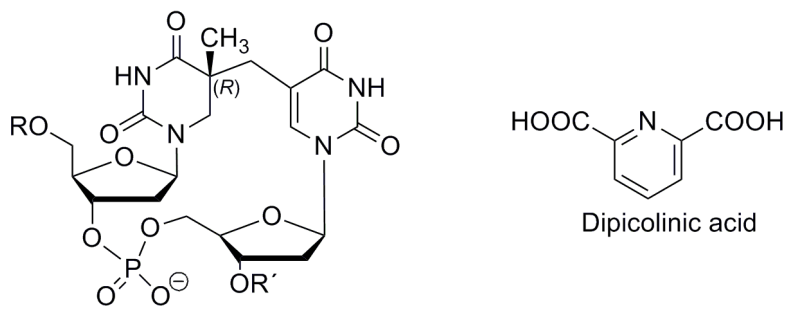

\section{Spore photoproduct (SP)}

$50 \quad$ Fig. 6 Structures of SP photoproduct and of dipicolinic acid

either at the $3^{\prime}$ - or at the $5^{\prime}$-end. Interestingly, DNA double helix structure induces a highly stereospecific formation of SP photoproducts (Fig. 6) ${ }^{87}$ their stucture has been recently assigned by 2D NMR studies combined with DFT 55 calculations. Thus, the natural SP results from addition of the thymine methyl group located on the $3^{\prime}$-end to the thymine C5 carbon located in the $5^{\prime}$-end, giving rise to a new chiral center with $R$ absolute configuration. ${ }^{87}$ Moreover, SP is only obtained as a Thy homodimer and has been detected both as 60 intrastrand and interstrand lesion. ${ }^{88,89}$

Indeed, SP is a quite peculiar bipyrimidine photoproduct, whose formation has been related to three important factors: ${ }^{85}$, 89,90 i) the low hydration level in spore core, ii) the binding of $\alpha / \beta$ type small, acid soluble protein (SASP), which converts ${ }_{65}$ DNA from B-like to A-like conformation, and iii) the presence of dipicolinic acid (pyridine-2,6-dicarboxylic acid DPA, Fig. 6) in the spore core (up to $10 \%$ of dry weight). The

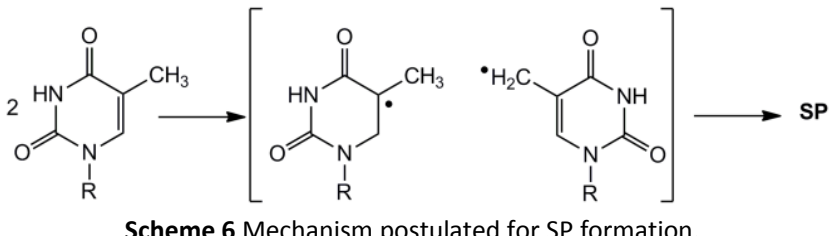

Scheme 6 Mechanism postulated for SP formation. 
photosensitising properties of this endogenous compound have been first proposed on the basis of the decrease of SP formation yield in spore strains lacking DPA. ${ }^{88,} 91$ This hypothesis has been further supported by studies in less 5 complex media like isolated DNA, TpT or Thd. ${ }^{49,87-89,92,93}$ In this context, UVC irradiation of DNA dry films in the presence of DPA has revealed the increase of SP, Thy $<>$ Thy, and to a lesser Thy $<>C y t$ and $\mathrm{Cyt}<>$ Thy relative yields, ${ }^{85,} 88$, ${ }^{91}$ whereas $\mathrm{Cyt}<>\mathrm{Cyt}$ and (6-4) photoproducts yields remain 10 almost unchanged. These data are in agreement with the role of DPA as triplet photosensitiser, acting as donor in TTET processes. Further pieces of evidence supporting the feasibility of such a process have been provided by the results of UVA-irradiation of Thd dry films in the presence of BP or 15 three pyridopsoralen derivatives (H-PyPs, MePyPs and 2NMePyPS, Fig. 3). ${ }^{19,} 49$ In these experiments, the six diastereoisomers of Thd $<>$ Thd and the $5 R^{*} / 5 S^{*}$ diastereoisomers of SP have been detected; their yields have been shown to depend on the nature of the photosensitiser. ${ }^{19}$ 20 As expected for triplet energy donors, their efficiency can be related to their excited state level, with H-PyPs being the most efficient, followed by MePyPs and 2N-MePyPs. Accordingly, no formation of Thd $<>$ Thd and SP has been observed for the donors with lower triplet energy like 3-carbethoxypsoralen, 525 methoxypsoralen and 8-MOP. ${ }^{19}$

Finally, it is noteworthy that in spite of the interesting SP photochemistry, the involved mechanism has not been investigated. ${ }^{85,94}$ The reaction may occur by coupling of the 5-thyminyl /5,6-dihydrothymin-5-yl radical pair generated as 30 a result of $\mathrm{H}$-abstraction from a ground state by a triplet excited Thy (Scheme 6). Alternatively, a concerted mechanism involving the methyl group of one Thy and the double bond of the second Thy has been proposed. Either the shorter lifetime of radical pairs (as compared with the free 35 radicals generated by radiation $)^{95,96}$ or the concerted nature of the process would account for the observed stereoselectivity.

\section{Theoretical calculations}

In spite of their importance in DNA damage formation, the Pyr triplet excited states are only now starting to be analysed 40 by theoretical studies. ${ }^{97-108}$ First principles calculation methods converge on the $\pi \pi^{*}$ nature of the lowest triplet state but not on their energy values, which have been reported over a large range (Table 3) depending on the method used for calculation and geometry optimisation. So far, the highest 45 level of approach has been CASPT2 based on CASSCF wave functions. However, because of the difficulties to apply this methodology for large molecules, a number of calculations have been performed at the density functional theory (DFT) level or by using the coupled cluster (CC) model.

50 In this context, the vertical excitation energy for Thy at the ground state geometry is situated between 336.7 and 382.1 $\mathrm{kJ} / \mathrm{mol}(3.49 \mathrm{eV}$ and $3.96 \mathrm{eV}$ ), while adiabatic excitation energy values range from 272.1 to $304.9 \mathrm{~kJ} / \mathrm{mol}$ (from 2.82 to $3.16 \mathrm{eV}$ ). Similar discrepancies have been reported for $\mathrm{Cyt}$ 55 and Ura (Table 3). Nevertheless, the general trend extracted from the calculated values is in agreement with the experimental data, i.e. the nucleobase with the lowest triplet excited state energy is Thy, while the highest triplet manifold corresponds to Cyt. Recently, the energetic gap between ${ }^{3}$ Thy ${ }^{*}$ 60 and ${ }^{3} \mathrm{Ura}^{*}$ has been rationalised in terms of the influence of C5-methylation. This substitution induces an up-shift of the $\pi$ HOMO while the acceptor $\pi^{*}$ LUMO is almost unaffected, thus resulting in a red shifted $\pi \rightarrow \pi^{*}$ transition. ${ }^{100}$

Table 3 Vertical and adiabatic $\pi \rightarrow \pi^{*}$ (singlet $\rightarrow$ triplet) transition energy 65 calculated for isolated Thy, Cyt and Ura and for their excimers (Pyr-Pyr).

Values are given in $\mathrm{kJ} / \mathrm{mol}$ and in $\mathrm{eV}$ in parentheses.

\begin{tabular}{|c|c|c|}
\hline & Vertical & Adiabatic \\
\hline Thy & $\begin{array}{c}336.7-337.7(3.49-3.50)^{a 97} \\
366.6-377.3(3.80-3.91)^{b 97} \\
358.9-372.4(3.72-3.86)^{c 98} \\
341.6(3.54)^{a 98} \\
373.4(3.87)^{c}{ }^{100} \\
376.3(3.90)^{c}{ }^{100} h y d, \\
382.1(3.96)^{c 100} a q \\
346.4(3.59)^{d 99} \\
368.6(3.82)^{c}\end{array}$ & $\begin{array}{c}272.1-275.0(2.82-2.85)^{a} \\
288.5-296.2(2.99-3.07)^{b} \\
299.1-304.9(3.10-3.16)^{c} \\
285.6(2.96)^{a} \text { 98 } \\
296.2(3.07)^{c}{ }^{c} 100 \\
276.9(2.87)^{d}{ }^{99}\end{array}$ \\
\hline Thy-Thy & & $227.7(2.36)^{d}{ }^{d 03}$ \\
\hline Cyt & $\begin{array}{c}347.3-350.2(3.60-3.63)^{a}{ }^{97} \\
361.8-383(3.75-3.97)^{b 97}\end{array}$ & $\begin{array}{l}293.3-298.1(3.04-3.09)^{a} \\
302.0-311.6(3.13-3.23)^{b}\end{array}$ \\
\hline & $\begin{array}{c}352.2(3.65)^{d}{ }^{101} \\
330.0-352.2(3.42-3.65)^{a}{ }^{105} \\
361.8-383.0(3.75-3.97)^{b} 105 \\
340.6(3.53)^{d}{ }^{d 06} \\
374.4(3.88)^{c}{ }^{107}\end{array}$ & $\begin{array}{c}293.3(3.04)^{d} \text { 101 } \\
284.6-298.1(2.95-3.09)^{a} \\
302.0-311.6(3.13-3.23)^{b} \\
287.5(2.98)^{d} 106\end{array}$ \\
\hline Cyt-Cyt & & $260.5(2.70)^{d}{ }^{d 03}$ \\
\hline Ura-Ura & $\begin{array}{c}370.5-383.0(3.84-3.97)^{c 98} \\
367.7(3.78)^{a 98} \\
384.0(3.98)^{c}{ }^{100} \\
387.9(4.02)^{c}{ }^{100} h y d \\
395.6(4.10)^{c}{ }^{100} a q \\
366.6(3.80)^{d}{ }^{108} \\
379.2(3.93)^{c}{ }^{107}\end{array}$ & $\begin{array}{c}284.6-383.0(2.95-3.97)^{a} \\
287.5-419.7(2.98-4.35)^{b} \\
312.6-319.4(3.24-3.31)^{c} \\
302.0(3.13)^{a}{ }^{a 8} \\
309.7(3.21)^{c}{ }^{c 100}\end{array}$ \\
\hline Calculated & sing ${ }^{a} \mathrm{DFT},{ }^{b} \mathrm{CCSD},{ }^{c} \mathrm{CC} 2,{ }^{c}$ & AASPT2//CASSCF \\
\hline
\end{tabular}

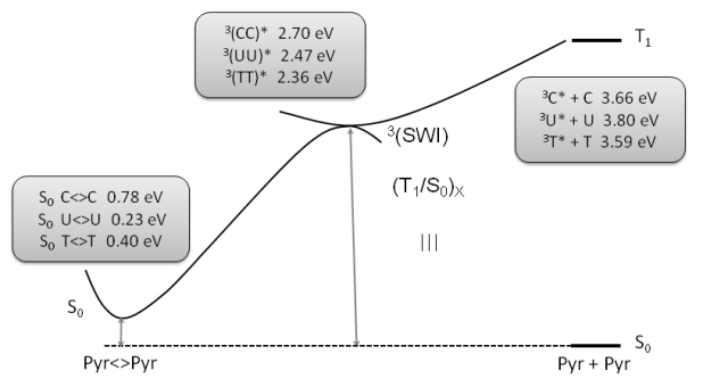

Scheme 7 Triplet mediated formation of Pyr $<>$ Pyr. Adapted from $70 \quad$ Serrano et al ${ }^{103}$ 
Computational studies are generally performed in vacuo i.e. without taking into account interaction between the target molecules and solvent. However, it is well established that such interactions may have a marked influence on the excited 5 state energy. In this context, the combined effect of hydration (energies denoted as hyd, Table 3) and solvent polarity, used to mimic aqueous environment (denoted $a q$ in Table 3 ) has only revealed a slight destabilisation of the lowest ${ }^{3} \pi \pi^{*}$ triplet state of Ura and Thy. ${ }^{100,}{ }^{109}$ Concerning the photochemical 10 reactivity of Pyr, theoretical calculations have mainly focused on the formation of cyclobutane dimers in a concerted process from the singlet excited state. ${ }^{110-114}$ However, as stated above, in the case of photosensitised $\mathrm{Pyr}<>\mathrm{Pyr}$ formation, [2+2] photocycloaddition occurs from the triplet manifold. In spite 15 of its importance, up to now this reaction pathway has only been considered by two research teams. ${ }^{102-104}$ In a first approach, calculations at the TD-DFT level have shown that triplet mediated photocycloaddition of Thy proceeds through an initial $\mathrm{C}^{-}-\mathrm{C6}^{\prime}$ bond formation, leading to a biradical 20 intermediate that subsequently crosslinks to the singlet surface, giving rise to Thy<>Thy. ${ }^{102}$ More recently, Pyr $<>$ Pyr formation has been computed by means of high level quantum chemical CASPT2//CASSCF calculations. ${ }^{103,}$ ${ }^{104}$ For a better approach to the nucleobase properties in DNA, 25 the triplet minima have been calculated for excimer arrangements formed by the parallel stacking of the bases (Scheme 7). In this context, a stabilisation relative to the isolated bases (denoted ${ }^{3} \mathrm{Pyr}^{*}+\mathrm{Pyr}$ in Scheme 7 ) is observed, giving rise to adiabatic energy values of $2.36,2.47,2.70 \mathrm{eV}$ 30 for Thy, Ura, and Cyt, respectively. This triplet excimer connects without any energy barrier with a stepwise intermediate ${ }^{3}$ (SWI), which exhibits a biradical character. Indeed, a covalent bond is formed between the C6 and C6' carbons, with the unpaired electrons and spin density located 35 on the two other ethylenic carbons ( $\mathrm{C} 5$ and $\left.\mathrm{C} 5^{\prime}\right)$. At this stage, the calculated C6-C6' bond lengths are 1.669, 1.660 and $1.664 \AA$ for Cyt, Ura, and Thy; by contrast, the interatomic $\mathrm{C5}^{-} \mathrm{C}^{\prime}$ ' distance is elongated (about $2.8 \AA$ ). Finally, ${ }^{3}$ (SWI) corresponds to a singlet-triplet crossing $40\left(\mathrm{~T}_{1} / \mathrm{S}_{0}\right)_{\mathrm{x}}$ structure leading to $\mathrm{Pyr}<>\mathrm{Pyr}$ ground state.

Thus, the efficiency of $\mathrm{Pyr}<>\mathrm{Pyr}$ photosensitisation depends on two factors. The first one is the effectiveness of the TTET process from the ${ }^{3} \mathrm{Phs}{ }^{*}$, which is related with the triplet state energy of the nucleobase $\left({ }^{3} \mathrm{Cyt}^{*}>{ }^{3} \mathrm{Ura}^{*}>{ }^{3}\right.$ Thy $\left.{ }^{*}\right)$; 45 this agrees with the experimental predominance of Thy<>Thy dimers vs. other Pyr combinations. The second factor deals with the efficiency of the intersystem crossing process toward the ground state of the photoproduct $\left(\mathrm{T}_{1} / \mathrm{S}_{0}\right)_{\mathrm{x}}$.

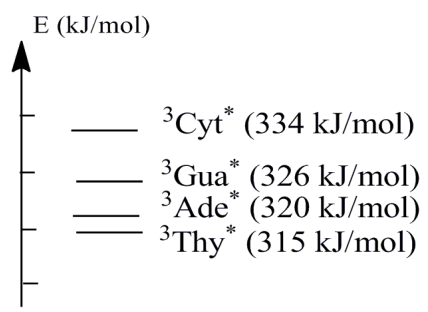

50 Fig. 7 Energies of DNA bases determined at $77 \mathrm{~K}$ in ethylene glycol/ $\mathrm{H}_{2} \mathrm{O}^{42}$

\section{Photophysics}

\subsection{Emission}

Thymine and its derivatives exhibit a pH-dependent phosphorescence emission. At $77 \mathrm{~K}$ under neutral conditions, 55 no signal is observed for diluted aqueous solutions. ${ }^{115-117}$ Conversely, at a $\mathrm{pH}$ higher than the pKa of Thy (ca. 9.6), ${ }^{118}$ the nucleobase in its anionic form emits at $445 \mathrm{~nm}$ with a decay time of 0.4-0.5 s. ${ }^{115,119,120}$ Parallel experiments have reported that at neutral $\mathrm{pH}$ and high concentrations (i.e. $10^{-3}$ $\left.{ }_{60} 10^{-2} \mathrm{M}\right)$, formation of aggregates gives rise to a phosphorescence emission at $470 \mathrm{~nm}$, with a lifetime of $0.2 \mathrm{~s}$ (Table 4). ${ }^{42,}{ }^{118}$ A similar spectrum has been detected by photosensitisation experiments using acetone to populate the Thd monophosphate (TMP) triplet excited state by an energy 65 transfer mechanism. ${ }^{42,120}$ Emission of Cyt and its derivatives has been studied to a lesser extent; ${ }^{43}, 120-125$ the obtained data are listed in Table 4.

Thus, as shown in Figure 7, Thy and Cyt are the nucleobases with the lowest and the highest triplet excited 70 state energies, respectively.

An intriguing result is the reported phosphorescence emission of native DNA. Indeed, by considering the higher phosphorescence quantum yield of purines, an overall emission closely related to these bases could be expected. ${ }_{75}$ However, the DNA spectrum does not exhibit the wellstructured band characteristic of purines, and the obtained quantum yield (Table 4) is 1 order of magnitude lower than that of adenosine monophosphate (AMP) or guanosine monophosphate (GMP). Hence, it has been proposed that 80 DNA emission arises from the triplet level of Thy residues. Accordingly, a more intense phosphorescence has been monitored for DNA with higher adenine (Ade) + Thy contents. $^{42,126}$ Different hypotheses have been postulated to explain the nature of the emissive residues. On the basis of the 85 lack of phosphorescence found for isolated Thy, emission was initially attributed to that of Thy anion formed by transfer of the thymine $\mathrm{N} 3$ proton across the Watson-Crick base pairing to the N1 nitrogen of adenine. ${ }^{115,} 119$ Nevertheless, this hypothesis has been contradicted by the phosphorescence 90 emission of Thy aggregates, which closely resembles that of DNA. This assignment has been further supported by the Thylike emission of 1,3-dimethylthymine in the presence of Ade, where the proton transfer is not possible. ${ }^{118,127}$ A similar conclusion has been drawn from single stranded DNA studies. ${ }_{95}^{42}$ Different explanations have been provided to account for the fact that Thy is the only emitting residue in DNA. The first one is related to its relatively low triplet state energy. It has been reported that, irrespective of the excited chromophore (Ade, Gua, Thy or Cyt), the only emission 100 observed in solutions containing mixtures of the nucleobases is that of ${ }^{3}$ Thy $^{*}$. $118,120,127$ This is consistent with energy transfer from the higher lying triplet excited states of Cyt, Ade or Gua to Thy in solution. Accordingly, a thymine emission has also been obtained for the dinucleotides dApT 105 and TpdA but also for polydAT. ${ }^{42,115,119,120,126,128} \mathrm{~A}$ similar deactivation channel towards ${ }^{3}$ Thy $^{*}$ has been postulated to explain the case of the whole DNA biomacromolecule. ${ }^{118,127}$ 
Table 4 Phosphorescence emission properties of pyrimidines, oligonucleotides and DNA at $77 \mathrm{~K}$. If not specified the values correspond to ethylene glycol/water glass at neutral $\mathrm{pH}$.

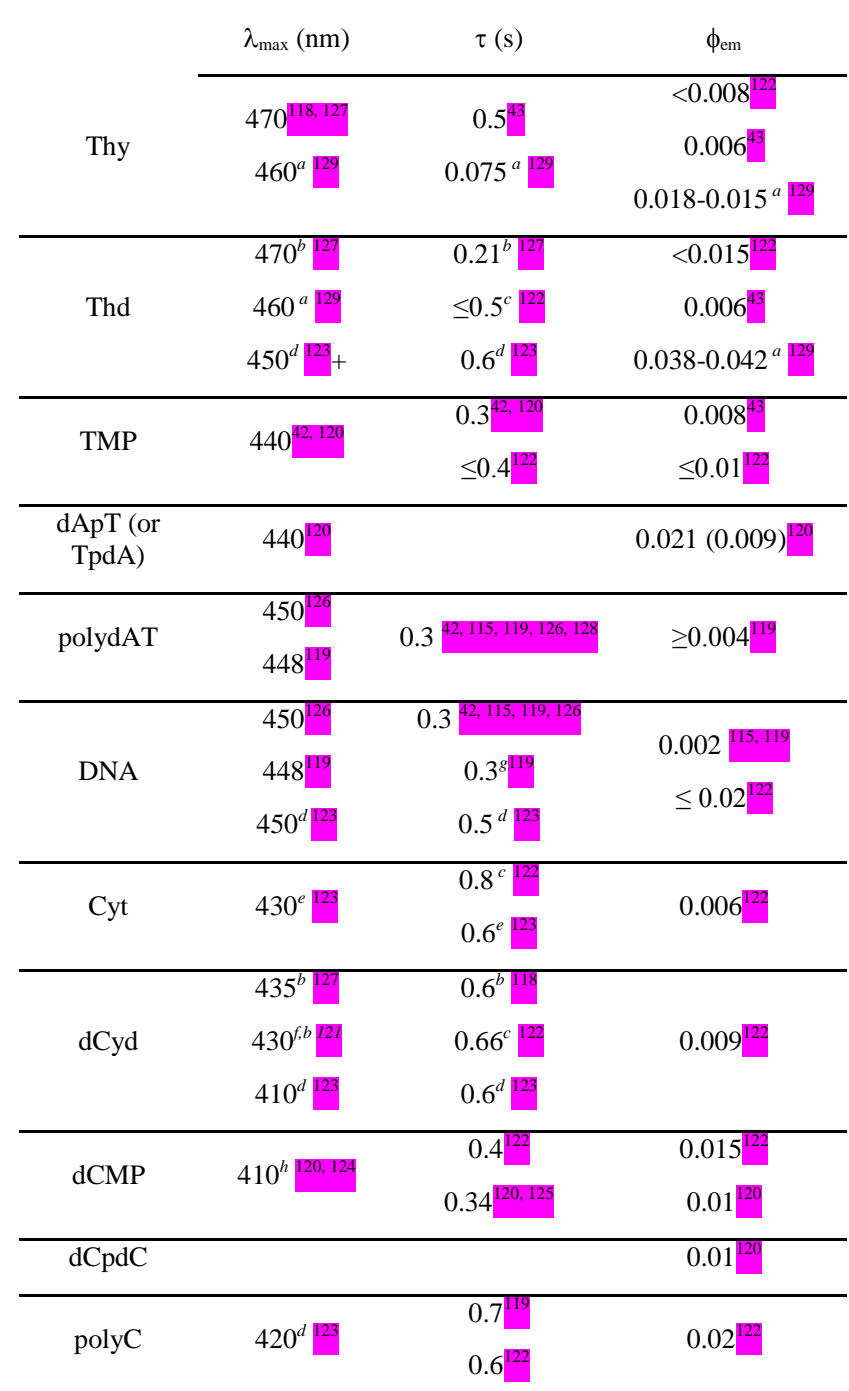

${ }^{a}$ 2-methyltetrahydrofuran, ${ }^{b}$ In $\mathrm{H}_{2} \mathrm{O} \mathrm{pH} 7 ;{ }^{c}$ in $\mathrm{CH}_{3} \mathrm{CH}_{2} \mathrm{OH} ;{ }^{d}: 0.25 \%$ 5 glucose in $0.1 \mathrm{M}$ sodium acetate- $\mathrm{H}_{2} \mathrm{O},{ }^{e}$ isopropanol/isopentane, ${ }^{f} \mathrm{H}_{2} \mathrm{O}$ /propylene glycol 1/1, ${ }^{g} \mathrm{H}_{2} \mathrm{O},{ }^{h} \mathrm{CH}_{3} \mathrm{OH} / \mathrm{H}_{2} \mathrm{O} 1 / 9 \mathrm{pH} 7$.

On the other hand, for the Gua - Cyt base pair, proton transfer at the singlet level can also be in the origin of their 10 lack of emission. ${ }^{118,119}$ Expectedly, DNA structure integrity is an important parameter. Temperature, solvent or $\mathrm{pH}$ conditions leading to denaturation of the double helix result in the typical blue shifted, more structured and longer lived phosphorescence emission of purines. ${ }^{119,} 126$

\section{${ }_{15} 5.2$ Laser flash photolysis studies}

\subsubsection{Intrinsic population of the triplet excited state upon direct excitation of Pyr bases}

Time-resolved techniques have been used to study the photophysical properties of singlet and triplet excited states of 20 individual nucleobases, nucleosides, nucleotides and oligonucleotides. ${ }^{130-142}$ In this context, it is generally accepted that the mechanisms involved in the generation of CPDs upon direct excitation of Thy are initiated by population of a singlet $\pi \pi^{*}$ state ${ }^{138,139,141}$ however, the nature of the subsequent 25 steps still remains a matter of discussion. Recent studies performed on Thd and $(\mathrm{T})_{20}$, using ultrafast time-resolved fluorescence and transient absorption spectroscopy, suggest that the $\pi \pi^{*}$ triplet excited state is a key player in the dimerisation reaction. Thus, similar spectra (with maxima at 30 350-400 nm) are obtained for both Thd and $(\mathrm{T})_{20}{ }^{136,141,142}$ They have been safely assigned to the T-T transition, which fully develops within picoseconds. The ISC quantum yield in aqueous solution has been estimated to be in the range 0.010.03 , with a higher value for $(\mathrm{T})_{20}$ than for Thd. The main 35 difference observed between the nucleoside and the oligonucleotide concerns the triplet lifetimes. Thus, $\tau_{\mathrm{T}}$ values in the subnanosecond domain have been determined for $(\mathrm{T})_{20}$; by contrast, ${ }^{3}$ Thd survives in the ns- $\mu$ s timescale, with a concentration-dependent lifetime. The role of triplet-mediated ${ }_{40}$ CPDs formation in $(T)_{20}$ supports a major contribution of this pathway also in natural DNA, where an extremely short $\tau_{\mathrm{T}}$ value would account for the previously reported inefficient quenching of CPDs formation by oxygen. Interestingly, the quantum yield of Pyr $<>P y r$ photodimerisation in double45 stranded genomic DNA is ca. 30 times lower than in $(\mathrm{T})_{\mathrm{n}}$ oligonucleotides. ${ }^{3}, 138,139$ Light absorption by non-thymine bases, low frequency of Thy doublets, and conformational restrictions may be in the origin of this effect.

Table 5 shows a selection of key photophysical parameters 50 (ISC quantum yield, as well as rate constants for unimolecular decay and self quenching, $\mathrm{k}_{0}$ ), determined for the triplet excited state of the Thy chromophore in the free base and in some derivatives. It also includes the corresponding molar absorption coefficients of the T-T absorption $\left(\varepsilon_{\mathrm{T}}\right)$, which have 55 been obtained applying an energy transfer method, with retinol as acceptor. ${ }^{130}$ The data indicate that formation of the triplet excited states upon direct UV-irradiation occurs actually in all cases. In spite of its biological relevance, the efficiency of this process is low, particularly in aqueous 60 medium.

Table 5 Photophysical properties of the triplet excited state of Thy and its derivatives in different solvents

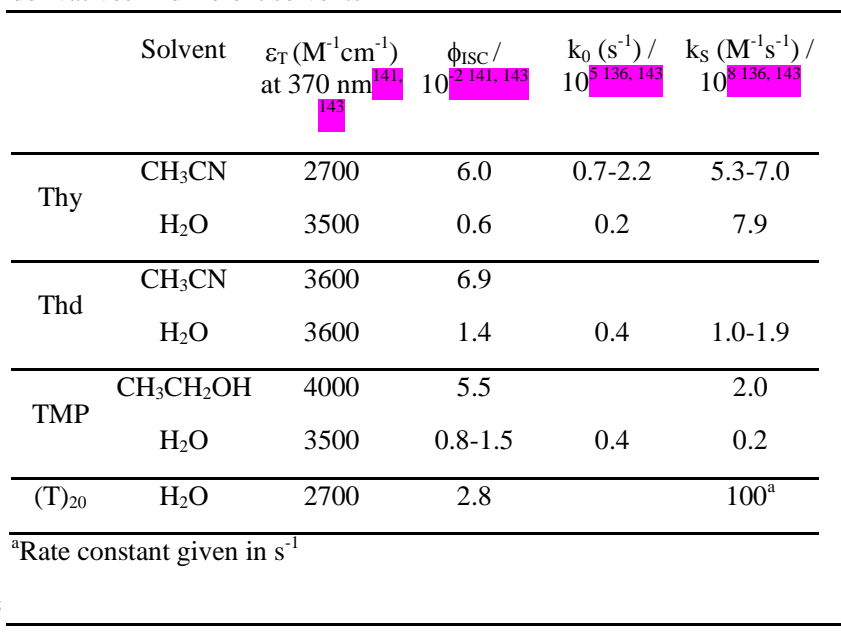


As stated above, triplet quenching by the ground states is associated with $\mathrm{Pyr}<>\mathrm{Pyr}$ dimerisation. Its rate constant can be determined according to:

$$
k_{o b s}=k_{0}+k_{S}\left[S_{0}\right]
$$

5 where $\mathrm{k}_{\mathrm{s}}$ stands for unimolecular decay and self quenching, respectively. As a matter of fact, the obtained values show that both deactivation pathways can compete, depending on the experimental conditions (solvent, concentration, etc.). It is worth noting that the highest $\mathrm{k}_{\mathrm{S}}$ corresponds to the 10 oligonucleotide, as expected for a concentration-independent process. A similar situation can be anticipated for natural DNA.

By contrast with Thy derivatives, the triplet excited states of Cyt, dCyd and dCyd monophosphate (dCMP) have not 15 been observed upon direct photolysis; this can be atributed to the low ISC quantum yields and molar absorption coefficients. $^{133}$

\subsubsection{Photosensitised generation of Pyr triplets}

20 A number of time-resolved studies have been performed on photosensitised reactions of Pyr bases, either alone or as substructures of more complex entities (nucleosides, nucleotides, oligonucleotides, etc.). In this context, Pyr dimerisation has been shown to occur via the triplet excited 25 state, using sensitisers such as acetone, acetophenone and propiophenone (Fig. 3). ${ }^{37,}{ }^{132-136}$ Acetone is particularly advantageous over other triplet sensitisers in kinetic studies for several reasons. First, acetone has a very high triplet energy $\left(\mathrm{E}_{\mathrm{T}} c a .330 \mathrm{~kJ}\right)$ and hence it can photosensitise both 30 Thy and Cyt bases. Second, its ISC quantum yield is close to the unity, so it is two orders of magnitude higher than those described for Pyr derivatives. Finally, the triplet-triplet absorption band of acetone does not interfere with observation of the growth of Pyr triplet excited states at $400 \mathrm{~nm}$, and does 35 not overlap with their whole transient absorption spectra (see Figure 8). ${ }^{133,136}$

After excitation of the photosensitiser, a number of processes may occur. The initial step is formation of the Phs first singlet excited state $\left({ }^{1} \mathrm{Phs}{ }^{*}\right)$. At this point, several 40 pathways can compete: fluorescence and internal conversion lead back to Phs, while intersystem crossing affords the triplet excited state $\left({ }^{3} \mathrm{Phs}^{*}\right)$. An ideal photosensitiser should have an ISC quantum yield close to 1 .

The Phs triplet energy relative to that of the Pyr derivative 45 is a key point to predict whether energy transfer can proceed. Thus, for irreversible energy transfer, the triplet energy of the donor must be at least $12 \mathrm{~kJ} / \mathrm{mol}$ higher than that of the acceptor. $^{135}$

In this context, the interaction between a variety of ketone 50 triplets and mononucleotides has been studied as a function of the relative energies of the $\mathrm{Phs}$-nucleotide pair. While ketones with $\mathrm{E}_{\mathrm{T}}$ higher than $305 \mathrm{~kJ} / \mathrm{mol}$ (acetone, acetophenone, propiophenone and 1-indanone) sensitise the generation of a transient absorption corresponding to ${ }^{3} \mathrm{TMP}^{*}$ in laser flash 55 photolysis (LFP), those with $\mathrm{E}_{\mathrm{T}}<305 \mathrm{~kJ} / \mathrm{mol}$ do not exhibit any triplet sensitisation capability, in spite of the significant quenching experimentally observed $\left(\mathrm{k}_{\mathrm{q}}>10^{8} \mathrm{M}^{-1} \mathrm{~s}^{-1}\right) .{ }^{134}$

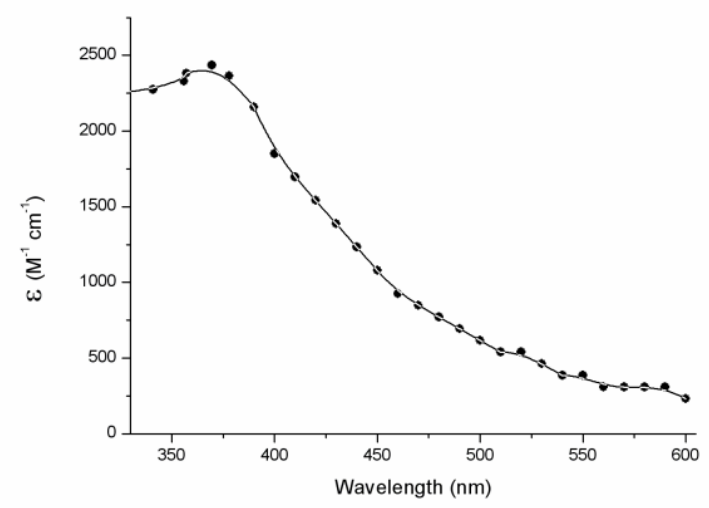

Fig. 8 Transient absorption spectrum of triplet excited of TMP, obtained 60 by energy transfer from acetone in deaerated aqueous solutions. ${ }^{134}$

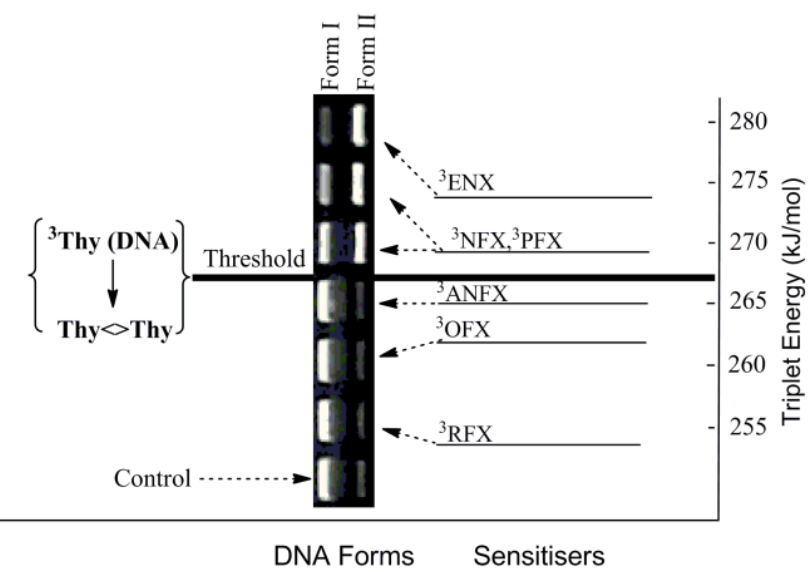

Fig. 9 Triplet energy of photosensitisers and electrophoretic analysis of DNA Form I (supercoiled native form) and Form II (single strand break) obtained from mixtures containing pBR322 and FQs $(20 \mu \mathrm{M})$ after 15 min

of irradiation and subsequent T4 Endo $V$ treatment. Adapted from Lhiaubet-Vallet et al. $^{72}$

Hence, the absolute value of TMP triplet energy has been estimated at ca. $310 \mathrm{~kJ} / \mathrm{mol}$. According to the Sandros' equation, this is consistent with the observation of energy 70 transfer from acetophenone $\left(\mathrm{E}_{\mathrm{T}}=310 \mathrm{~kJ} / \mathrm{mol}\right)$, but not from 3 methoxyacetophenone $\left(\mathrm{E}_{\mathrm{T}}=303 \mathrm{~kJ} / \mathrm{mol}\right) .{ }^{135}$

Benzophenone derivatives, with $\mathrm{E}_{\mathrm{T}}=290 \mathrm{~kJ} / \mathrm{mol}$, lower than that of TMP, have been shown to photosensitise Thd $<>$ Thd formation at high nucleoside concentrations, in 75 competition with a more favoured Paterno-Büchi photocycloaddition. ${ }^{31}$ This explains the efficient quenching $\left(\mathrm{k}_{\mathrm{q}}=5.1 \times 10^{8} \mathrm{M}^{-1} \mathrm{~s}^{-1}\right)$ observed in acetonitrile. Remarkably, LFP studies on $(S)$ - and $(R)$ - KP have shown a significant enantiodifferentiation in the quenching rate constants by ${ }_{80}$ Thd. $^{55}$

In DNA, the photosensitiser triplet energy required for $\mathrm{Pyr}<>\mathrm{Pyr}$ formation has been progressively shifted from $c a$. $300 \mathrm{~kJ} / \mathrm{mol}$ (methoxyacetophenones) ${ }^{134}$ down to $290 \mathrm{~kJ} / \mathrm{mol}$ (benzophenone and phthalimidine derivatives) ${ }^{31,48,55,68}$ and 85 more recently to $267 \mathrm{~kJ} / \mathrm{mol}(\mathrm{FQs})^{71,}{ }^{72}$. A series of fluoroquinolones (FQs), including ENX, pefloxacin (PFX), 
NFX, ANFX, OFX and rufloxacin (RFX) have been

for Pyr $<>$ Pyr dimers formation in DNA. At FQ concentrations investigated to determine their potential as photosensitisers

Table 6 Rate constants of energy transfer from FQs to flurbiprofen (FBP), 4-biphenylcarboxylic acid (BPC) and naproxen (NP) and estimated values of 5 the triplet excited state energies of $\mathrm{FQs}^{72}$

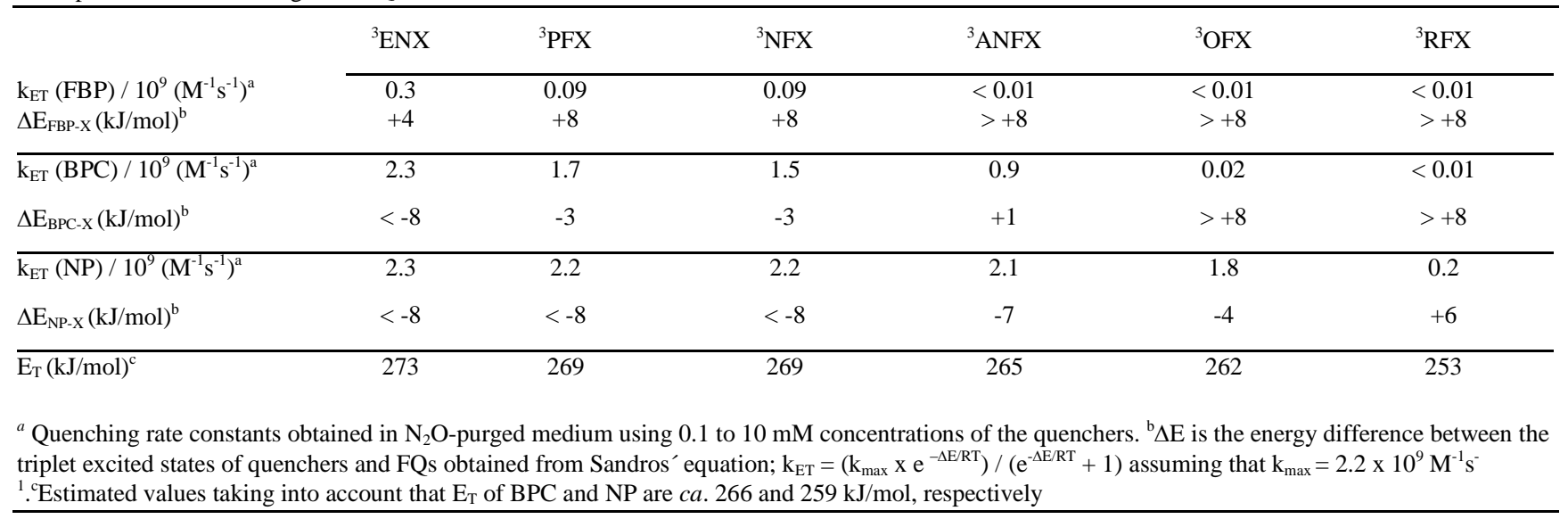

for Pyr $<>$ Pyr dimers formation in DNA. At FQ concentrations 10 and light doses insufficient to produce direct single strand breaks, ENX, PFX and NFX are able to produce Pyr $<>P y r$ dimers in DNA as revealed by enzymatic treatment with T4 endonuclease V. By contrast, ANFX, OFX and RFX are inefficient in this assay (Fig. 9). This information has been 15 combined with the absolute values of the triplet energies of ENX, PFX, NFX, ANFX, OFX and RFX, estimated by means of LFP, using flurbiprofen (FBP), 4-biphenylcarboxylic acid (BPC) and naproxen (NP) as energy acceptors (Table 6). ${ }^{71,72}$

All the results indicate that the threshold $\mathrm{E}_{\mathrm{T}}$ value required 20 for a given compound to become a potential DNA photosensitiser via Thy<>Thy formation is in the range defined by the triplet energies of NFX and ANFX (265-269 kJ/mol, see Fig. 9).

Moreover, when the Phs $\mathrm{E}_{\mathrm{T}}$ is lower than the threshold, 25 triplet quenching by $\mathrm{Pyr}$ derivatives can only occur by pathways not involving energy transfer. This is the case for menadione, whose $\mathrm{E}_{\mathrm{T}}$ is ca. $243 \mathrm{~kJ} / \mathrm{mol}$. The high quenching rate constants (between 1.0 and $2.5 \times 10^{9} \mathrm{M}^{-1} \mathrm{~s}^{-1}$ ) correspond to electron transfer, generating menadione radical anion and ${ }_{30}$ Pyr radical cations (Scheme 3). ${ }^{144}$

As stated above, in the case of Cyt, dCyd and dCMP, the triplet energy is higher than that reported for Thy, Thd and TMP. Therefore their triplet excited states are difficult to detect when both types of Pyr units are present, owing to 35 deactivation via base-to-base energy transfer. Nonetheless, the transient absorption spectra have been recorded using acetone as Phs. From this type of experiment, it has been possible to determine the rate constants of unimolecular decay $\left(\mathrm{k}_{0}\right)$, as well as those of self quenching $\left(\mathrm{k}_{\mathrm{s}}\right)$ (Table 7). ${ }^{133}$

40 Table 7 Kinetic parameters of Cyt and derivatives in aqueous solutions

\begin{tabular}{cccc} 
& $\mathrm{k}_{0} / 10^{4} \mathrm{~s}^{-1}$ & $\mathrm{k}_{\mathrm{S}} / 10^{8} \mathrm{M}^{-1} \mathrm{~s}^{-1}$ & $\mathrm{k}_{\mathrm{q} 1}$ (acetone) $/ 10^{9} \mathrm{M}^{-1} \mathrm{~s}^{-1}$ \\
\cline { 2 - 4 } Cyt & 5.5 & 4.2 & 3.8 \\
$\mathrm{dCyd}$ & 7.6 & 2.4 & 4.5 \\
$\mathrm{dCMP}$ & 9.4 & 1.8 & 5.1
\end{tabular}

\section{Summary and Outlook}

Triplet excited states play a key role in the dimerisation of 45 pyrimidine bases, not only in photosensitised processes, but also upon direct UV-irradiation. Cyclobutane pyrimidine dimers (CPDs) are by far the most relevant Pyr photoproducts obtained by sensitisation. Spore photoproducts may also be formed through this pathway; however, they are not found in 50 mammals or other higher organisms. By contrast, there is no evidence for photosensitised reactions leading to pyrimidine (6-4) pyrimidone photoproducts. The mechanism of direct UVA-induced CPDs formation is still controversial; as DNA hardly absorbs in this wavelength range, the involvement of 55 endogenous photosensitisers cannot be safely ruled out. In spite of the importance of the triplet pathway in $\mathrm{Pyr}$ photodimerisation, further efforts are needed to achieve a better understanding by means of theoretical calculations. Issues such as the lack of pyrimidine (6-4) pyrimidone 60 formation or the special conditions required to obtain spore photoproducts from the triplet manifold should be explained. Finally, the triplet energy of thymine in DNA has been found to be much lower than that of the free base or the nucleoside. As this is a key parameter to anticipate the potential ${ }_{65}$ photocarcinogenicity of photosensitisers, it seems interesting to clarify how the various structural features (sequence, $\pi$ stacking, base pairing, etc.) modulate its actual value in the different microenvironments of the biomacromolecule.

\section{Acknowledgements}

70 Financial support from the Spanish Government (CTQ200913699, CTQ2009-14196, JAE Doc fellowship for M.C.C. and Ramon y Cajal contract for V. V-L.) and EU (CM0603) is gratefully acknowledged.

\section{Notes and references}

$75{ }^{a}$ Instituto de Tecnología Química UPV-CSIC, Universidad Politécnica de Valencia, Avda de los Naranjos s $n$, 46022 Valencia, Spain Fax: +34963879444 ; Tel: +34 963877807; Email:mmiranda@qim.upv.es 


\section{See DOI: $10.1039 / \mathrm{b} 000000 \mathrm{x} /$}

1. T. L. Oncology, Lancet Oncol., 2009, 10, 835

2. T. WHO, Fact Sheet $n^{\circ} 287,2010$.

5 3. S. Mouret, C. Baudouin, M. Charveron, A. Favier, J. Cadet and T. Douki, Proc. Natl. Acad. Sci. USA, 2006, 103, 13765-13770.

4. R. D. Ley, Cancer Res., 1997, 57, 3682-3684.

5. R. B. Setlow, E. Grist, K. Thompson and D. Woodhead, Proc. Natl Acad. Sci. USA, 1993, 90, 6666-6670.

10 6. P. J. Rochette, J.-P. Therrien, R. Drouin, D. Perdiz, N. Bastien, E. A. Drobetsky and E. Sage, Nucleic Acids Res., 2003, 31, 2786-2794.

7. D. L. Mitchell, A. A. Fernandez, R. S. Nairn, R. Garcia, L. Paniker, D. Trono, H. D. Thames and I. Gimenez-Conti, Proc. Natl. Acad. Sci. USA, 2010, 107, 9329-9334.

15 8. T. Douki, A. Reynaud-Angelin, J. Cadet and E. Sage, Biochemistry, 2003, 42, 9221-9226

9. A. R. Young, C. S. Potten, O. Nikaido, P. G. Parsons, J. Boenders, J. M. Ramsden and C. A. Chadwick, J. Invest. Dermatol., 1998, 111, 936-940.

20 10. M. S. Cooke, M. D. Evans, R. M. Burd, K. Patel, A. Barnard, J. Lunec and P. E. Hutchinson, J. Invest. Dermatol., 2001, 116, 281285.

11. S. Mouret, C. Phillippe, J. Gracia-Chantegrel, A. Banyasz, S. Karpati, D. Markovitsi and T. Douki, Org. Biomol. Chem., 2010, 8, 17061711.

12. Y. Jiang, M. Rabbi, M. Kim, C. H. Ke, W. Lee, R. L. Clark, P. A. Mieczkowski and P. E. Marszalek, Biophys. J., 2009, 96, 1151-1158.

13. R. M. Tyrrell and S. M. Keyse, J. Photochem. Photobiol. B: Biol., 1990, 4, 349-361.

30 14. A. Besaratinia, T. W. Synold, H.-H. Chen, C. Chang, B. Xi, A. D. Riggs and G. P. Pfeifer, Proc. Natl. Acad. Sci. USA, 2005, 102, 10058-10063.

15. Z. Kuluncsics, D. Perdiz, E. Brulay, B. Muel and E. Sage, J. Photochem. Photobiol. B: Biol., 1999, 49, 71-80.

35 16. D. Perdiz, P. Gróf, M. Mezzina, O. Nikaido, E. Moustacchi and E. Sage, J. Biol. Chem., 2000, 275, 26732-26742.

17. J. Cadet, S. Courdavault, J. L. Ravanat and T. Douki, Pure Appl. Chem., 2005, 77, 947-961.

18. R. Costalat, J. Blais, J. P. Ballini, A. Moysan, J. Cadet, O. Chalvet and P. Vigny, Photochem. Photobiol., 1990, 51, 255-262.

19. A. Moysan, A. Viari, P. Vigny, L. Voituriez, J. Cadet, E. Moustacchi and E. Sage, Biochemistry, 1991, 30, 7080-7088.

20. R. S. Stern, L. E. J. and L. Väkevä, J. Natl. Cancer Inst., 1998, 90, 1278-1284.

45 21. A. R. Young, J. Photochem. Photobiol. B: Biol., 1990, 6, $237-247$.

22. T. E. Spratt, S. S. Schultz, D. E. Levy, D. Chen, G. Shlueter and G. M. Williams, Chem. Res. Toxicol., 1999, 12, 809-815.

23. S. Sauvaigo, T. Douki, F. Odin, S. Caillat, J. L. Ravanat and J. Cadet, Photochem. Photobiol., 2001, 73, 230-237.

50 24. M. C. Cuquerella, F. Bosca, M. A. Miranda, A. Belvedere, A. Catalfo and G. De Guidi, Chem. Res. Toxicol., 2003, 16, 562-570.

25. V. Lhiaubet-Vallet, F. Bosca and M. A. Miranda, Photochem. Photobiol., 2009, 85, 861-868.

26. M. Mäkinen, P. D. Forbes and F. Stenbäck, J. Photochem. Photobiol. B: Biol., 1997, 37, 182-187.

27. G. Klecak, F. Urbach and H. Urwyler, J. Photochem. Photobiol. B: Biol., 1997, 37, 174-181.

28. B. E. Jonhson, N. K. Gibbs and J. Ferguson, J. Photochem. Photobiol. B: Biol., 1997, 37, 171-173.

60 29. T. Itoh, H. Miyauchi-Hashimoto, A. Sugihara, K. Tanaka and T. Horio, J. Invest. Dermatol., 2005, 125, 554-559.

30. K. Sandros, Acta Chem. Scand., 1964, 18, 2355-2374

31. S. Encinas, N. Belmadoui, M. J. Climent, S. Gil and M. A. Miranda, Chem. Res.Toxicol., 2004, 17, 857-862.

65 32. H. Morrison and R. Kleopfer, J. Am. Chem. Soc., 1968, 90, 50375038.

33. P. J. Wagner and D. J. Bucheck, J. Am. Chem. Soc., 1970, 92, 181185.

34. J. Cadet, L. Voituriez, F. E. Hruska, L.-S. Kan, F. A. A. de Leeuw and C. Altona, Can. J. Chem., 1985, 63, 2861-2868.

35. A. J. Varghese, Photochem. Photobiol., 1972, 15, 113-118.
36. A. A. Lamola, Photochem. Photobiol., 1968, 7, 619-632.

37. C. L. Greenstock and H. E. Johns, Biochem. Biophys. Res. Commun., 1968, 30, 21-27.

75 38. S. R. Aliwell, B. S. Martincigh and L. F. Salter, J. Photochem. Photobiol. A: Chem., 1993, 71, 137-146.

39. R. Kleopfer and H. Morrison, J. Am. Chem. Soc., 1972, 94, 255-264.

40. N. Chouini-Lalanne, M. Defais and N. Paillous, Biochem. Pharmacol., 1998, 55, 441-446.

80 41. M. L. Meistrich and A. A. Lamola, J. Mol. Biol., 1972, 66, 83-95.

42. A. A. Lamola, M. Gueron, T. Yamane, J. Eisinger and R. G. Shulman, J. Chem. Phys., 1967, 47, 2210-2217.

43. P. I. Hønnas and H. B. Steen, Photochem. Photobiol., 1970, 11, $67-$ 76.

85 44. I. von Wilucki, H. Matthäus and C. H. Krauch, Photochem. Photobiol., 1967, 6, 497-500.

45. D. Elad, C. Krüger and G. M. J. Schmidt, Photochem. Photobiol., 1967, 6, 495-496.

46. B. H. Jennings, S.-C. Pastra and J. L. Wellington, Photochem.

$90 \quad$ Photobiol., 1970, 11, 215-226.

47. E. Ben-Hur, D. Elad and R. Ben-Ishai, Biochim. Biophys. Acta, 1967, 149, 355-360.

48. T. Delatour, T. Douki, C. D'Ham and J. Cadet, J. Photochem. Photobiol. B: Biol., 1998, 44, 191-198.

95 49. T. Douki, M. Court and J. Cadet, J. Photochem. Photobiol. B: Biol., 2000, 54, 145-154.

50. N. Belmadoui, S. Encinas, M. J. Climent, S. Gil and M. A. Miranda, Chem. Eur. J., 2006, 12, 553-561.

51. G. Prakash and D. E. Falvey, J. Am. Chem. Soc., 1995, 117, 11375 11376.

52. K. Nakatani, T. Yoshida and I. Saito, J. Am. Chem. Soc., 2002, 124 2118-2119.

53. A. J. Varghese, Photochem. Photobiol., 1975, 21, 147-151.

54. J. Trzcionka, V. Lhiaubet-Vallet, C. Paris, N. Belmadoui, M. J. Climent and M. A. Miranda, ChemBioChem, 2007, 8, 402-407.

55. V. Lhiaubet-Vallet, S. Encinas and M. A. Miranda, J. Am. Chem. Soc., 2005, 127, 12774-12775.

56. M. E. Umlas, W. A. Frankling, G. L. Chan and W. A. Haseltine, Photochem. Photobiol., 1985, 42, 265-273.

110 57. F.-T. Liu and N. C. Yang, Biochemistry, 1978, 17, 4865-4876.

58. W. Mu, Q. Han, Z. Luo and Y. Wang, Anal. Biochem., 2006, 353, 117-123.

59. M. Kaneko, A. Matsuyama and C. Nagata, Nucleic Acids Res., 1979, 6, 1177-1187.

115 60. M. W. Logue and N. J. Leonard, J. Am. Chem. Soc., 1972, 94, 2842 2846.

61. T. M. G. Koning, J. J. G. van Soest and R. Kaptein, Eur. J. Biochem., 1991, 195, 29-40.

62. N. J. Leonard, R. S. McCredie, M. W. Logue and R. L. Cundall, J.

120 Am. Chem. Soc., 1973, 95, 2320-2324.

63. J. Yamamoto, K. Nishiguchi, K. Manabe, C. Masutani, F. Hanaoka and S. Iwai, Nucleic Acids Res., 2010, 1-11.

64. R. O. Rahn and L. C. Landry, Biochim. Biophys. Acta 1971, 247, 197-206.

125 65. J. L. Hosszu and R. O. Rahn, Biochem. Biophys. Res. Commun., 1967, 29, 327-330.

66. R. B. Setlow and W. L. Carrier, J. Mol. Biol., 1966, 17, 237-254.

67. V. Lhiaubet, N. Paillous and N. Chouini-Lalanne, Photochem. Photobiol., 2001, 74, 670-678.

130 68. V. Lhiaubet-Vallet, J. Trzcionka, S. Encinas, M. A. Miranda and N. Chouini-Lalanne, J. Phys. Chem. B, 2004, 108, 14148-14153.

69. F. Bourre, G. Renault, P. C. Seawell and A. Sarasin, Biochimie, 67, 293-299.

70. J. Trzcionka, V. Lhiaubet-Vallet and N. Chouini-Lalanne, Photochem. Photobiol. Sci., 2004, 3, 226-230.

71. F. Bosca, V. Lhiaubet-Vallet, M. C. Cuquerella, J. V. Castell and M. A. Miranda, J. Am. Chem. Soc., 2006, 128, 6318-6319.

72. V. Lhiaubet-Vallet, M. C. Cuquerella, J. V. Castell, F. Bosca and M. A. Miranda, J. Phys. Chem. B, 2007, 111, 7409-7414.

140 73. L. Marrot, J. P. Belaidi, C. Jones, P. Perez, L. Riou, S. A. and J. R. Meunier, J. Invest. Dermatol., 2003, 121, 596-606. 
74. N. J. Traynor and N. K. Gibbs, Photochem. Photobiol., 1999, 70, 957-959.

75. A. A. Lamola, Pure Appl. Chem., 1970, 24, 599-610.

76. A. A. Lamola and T. Yamane, Proc. Natl. Acad. Sci. USA, 1967, 58, 443-446.

77. M. H. Patrick and J. M. Snow, Photochem. Photobiol., 1977, 25, 373384.

78. L. A. Guillo, J. Blais, P. Vigny and A. Spassky, Photochem. Photobiol., 1995, 61, 331-335.

10 79. K. S. Robinson, N. J. Traynor, H. Moseley, J. Ferguson and J. A. Woods, Toxicol. In Vitro, 2010, 24, 1126-1132.

80. N. J. Traynor, B. Kratzer, M. A. Miranda and N. K. Gibbs, Br. J. Dermatol., 1999, 140, 784.

81. L. Marrot and J.-R. Meunier, J. Am. Acad. Dermatol., 2008, 58, S139-S148.

82. P. Walrant, R. Santus and M. Charlier, Photochem. Photobiol., 1976, 24, 13-19.

83. K. Bolton, B. S. Martincigh and L. F. Salter, J. Photochem Photobiol. A: Chem., 1992, 63, 241-248.

20 84. S. R. Aliwell, B. S. Martincigh and L. F. Salter, J. Photochem. Photobiol. A: Chem., 1993, 71, 147-153.

85. C. Desnous, D. Guillaume and P. Clivio, Chem. Rev., 2010, 110, 1213-1232.

86. J. E. J. Donnellan and R. B. Setlow, Science, 1965, 149, 308-310.

25 87. C. Mantel, A. Chandor, D. Gasparutto, T. Douki, M. Atta, M. Fontecave, P.-A. Bayle, J.-M. Mouesca and M. Bardet, J. Am. Chem. Soc., 2008, 130, 16978-16984.

88. T. Douki, B. Setlow and P. Setlow, Photochem. Photobiol. Sci., 2005, 4, 591-597.

30 89. T. Douki, G. Laporte and J. Cadet, Nucleic Acids Res., 2003, 31, 3134-3142.

90. W. L. Nicholson, B. Setlow and P. Setlow, Proc. Natl. Acad. Sci. USA, 1991, 88, 8288-8292.

91. B. Setlow and P. Setlow, Appl. Environ. Microbiol., 1993, 59, 64035643.

92. R. O. Rahn and J. L. Hosszu, Biochim. Biophys. Acta 1969, 190, 126 131

93. T. Douki and J. Cadet, Photochem. Photobiol. Sci., 2003, 2, 433-436.

94. A. J. Varghese, Biochemistry, 1970, 9, 4781-4787.

40 95. M. Gromova, E. Balanzat, B. Gervais, R. Nardin and J. Cadet, Int. J. Radiat. Biol., 1998, 74, 81-97.

96. A. A. Shaw and J. Cadet, J. Chem. Soc., Perkin Trans. 2, 1990, 2063 2070.

97. M. T. Nguyen, R. Zhang, P.-C. Nam and A. J. Ceulemans, J. Phys. Chem. A, 2004, 108, 6554-6561.

98. M. Etinski, T. Fleig and C. M. Marian, J. Phys. Chem. A, 2009, 113, $11809-11816$.

99. J. J. Serrano-Pérez, R. González-Luque, M. Merchán and L. SerranoAndrés, J. Phys. Chem. B, 2007, 111, 11880-11883.

50 100.M. Etinski and C. M. Marian, Phys. Chem. Chem. Phys., 2010, 12, 4915-4923

101.M. Merchán, L. Serrano-Andrés, M. A. Robb and L. Blancafort, J. Am. Chem. Soc., 2005, 127, 1820-1825.

102.R. B. Zhang and L. A. Eriksson, J. Phys. Chem. B, 2006, 110, 75567562.

103.T. Climent, I. González-Ramírez, R. Gonzalez-Luque, M. Merchán and L. Serrano-Andres, J. Phys. Chem. Lett., 2010, 1, 2072-2076.

104.D. Roca-Sanjuán, G. Olaso-González, I. González-Ramírez, L. Serrano-Andrés and M. Merchán, J. Am. Chem. Soc., 2008, 130, 10768-10779.

105.R. Abouaf, J. Pommier, H. Dunet, P. Quan, P. C. Nam and M. T. Nguyen, J Chem Phys, 2004, 121, 11668-11674.

106.R. González-Luque, T. Climent, I. González-Ramírez, M. Merchán and L. Serrano-Andrés, J. Chem. Theory Comput., 2010, 6, 2103 2114.

107.T. Fleig, S. Knecht and C. Hättig, J. Phys. Chem. A, 2007, 111, $5482-$ 5491.

108.T. Climent, R. González-Luque, M. Merchán and L. Serrano-Andrés, Chem. Phys. Lett., 2007, 441, 327-331.

70 109.A. M. Rasmussen, M. C. Lind, S. Kim and H. F. Schaefer, J. Chem. Theor. Comput., 2010, 6, 930-939.
110.M. Boggio-Pasqua, G. Groenhof, L. V. Shäfer, H. Grubmüller and M A. Robb, J. Am. Chem. Soc., 2007, 129, 10996-10997.

111.M. Merchán, R. González-Luque, T. Climent, L. Serrano-Andrés, E. Rodríguez, M. Reguero and D. Peláez, J. Phys. Chem. B, 2006, 110, 26471-26476.

112.B. Durbeej and L. A. Eriksson, J. Photochem. Photobiol. A: Chem., 2002, 152, 95-101.

113.J. J. Serrano-Perez, I. Gonzalez-Ramirez, P. B. Coto, M. Merchan and L. Serrano-Andres, J. Phys. Chem. B, 2008, 112, 14096-14098.

114.L. Blancafort and A. Migani, J. Am. Chem. Soc., 2007, 129, 14540 14541 .

115.R. O. Rahn, R. G. Shulman and J. W. Longworth, Proc. Natl. Acad. Sci. USA, 1965, 53, 893-896.

85 116.R. Bersohn and I. Isenberg, Biochem. Biophys. Res. Commun., 1963, 12, 205-208

117.R. Bersohn and I. Isenberg, J. Chem. Phys., 1964, 40, 3175-3180.

118.C. Hélène, Biochem. Biophys. Res. Commun., 1966, 22, 237-242.

119.R. O. Rahn, R. G. Shulman and J. W. Longworth, J. Chem. Phys, 1966, 45, 2955-2965.

120.J. Eisinger and R. G. Shulman, Science, 1968, 161, 1311-1319.

121.T. Montenay-Garestier and C. Hélène, Biochemistry, 1970, 9, 2865 2870 .

122.H. Görner, J. Photochem. Photobiol. B: Biol., 1990, 5, 359-377.

95 123.V. Kleinwachter, J. Drobnik and L. Augenstein, Photochem. Photobiol., 1968, 7, 485-497.

124.J. J. Aaron, W. J. Spann and J. D. Winefordner, Talanta, 1973, 20, 855-865.

125.M. Guéron, J. Eisinger and R. G. Shulman, J. Chem. Phys, 1967, 47, 4077-4091.

126.I. Isenberg, R. Rosenbluth and S. L. J. Baird, Biophys. J., 1967, 7, 365-373.

127.C. Hélène and T. Montenay-Garestier, Chem. Phys. Lett., 1968, 2, 25-28.

105 128.J. Eisinger and R. G. Shulman, J. Mol. Biol., 1967, 28, 445-449.

129.R. S. Becker and G. Kogan, Photochem. Photobiol., 1980, 31, 5-13.

130.C. Salet, R. Bensasson and R. S. Becker, Photochem. Photobiol., $1979, \mathbf{3 0}, 325-329$

131.C. Salet and R. Bensasson, Photochem. Photobiol., 1975, 22, 231 $110 \quad 235$.

132.K. Kasama, A. Takematsu and S. Arai, J. Phys. Chem., 1982, 86, 2420-2427.

133.Z.-h. Zuo, S.-d. Yao, J. Luo, W.-f. Wang, J.-s. Zhang and N.-y. Lin, J. Photochem. Photobiol. B: Biol., 1992, 15, 215-222.

115 134.I. G. Gut, P. D. Wood and R. W. Redmond, J. Am. Chem. Soc., 1996, 118, 2366-2373.

135.P. D. Wood and R. W. Redmond, J. Am. Chem. Soc., 1996, 118 4256.

136.Q. H. Song, W. Z. Lin, S. D. Yao and N. Y. Lin, J. Photochem. 120 Photobiol. A: Chem., 1998, 114, 181-184.

137.C. E. Crespo-Hernández, B. Cohen, P. M. Hare and B. Kohler, Chem. Rev., 2004, 104, 1977-2019.

138.E. Samoylova, H. Lippert, S. Ullrich, I. V. Hertel, W. Radloff and T. Schultz, J. Am. Chem. Soc., 2005, 127, 1782-1786.

125 139.W. J. Schreier, T. E. Schrader, F. O. Koller, P. Gilch, C. E. CrespoHernández, V. N. Swaminathan, T. Carell, W. Zinth and B. Kohler, Science, 2007, 315, 625-629.

140.P. M. Hare, C. T. Middleton, K. I. Mertel, J. M. Herbert and B. Kohler, Chem. Phys., 2008, 347, 383-392.

130 141.W. M. Kwok, C. Ma and D. L. Phillips, J. Am. Chem. Soc., 2008, 130, 5131-5139

142.S. Marguet and D. Markovitsi, J. Am. Chem. Soc., 2005, 127, 57805781 .

143.R. V. Bensasson, E. J. Land and T. G. Truscott, Laser Photolysis and 135 Pulse Radiolysis, Oxford, 1983.

144.J. R. Wagner, J. E. van Lier and L. J. Johnston, Photochem Photobiol, 1990, 52, 333-343. 